\title{
Disruption of Glycine Transporter 1 Restricted to Forebrain Neurons Is Associated with a Procognitive and Antipsychotic Phenotypic Profile
}

\author{
Benjamin K. Yee, ${ }^{1}$ Ela Balic, ${ }^{2}$ Philipp Singer, ${ }^{1}$ Cornelia Schwerdel, ${ }^{2}$ Thomas Grampp, ${ }^{2}$ Laetitia Gabernet, ${ }^{2}$ \\ Irene Knuesel, ${ }^{1}$ Dietmar Benke, ${ }^{2}$ Joram Feldon, ${ }^{1}$ Hanns Mohler, ${ }^{2,3}$ and Detlev Boison ${ }^{4}$ \\ ${ }^{1}$ Laboratory of Behavioral Neurobiology, Swiss Federal Institute of Technology, 8603 Schwerzenbach, Switzerland, ${ }^{2}$ Institute of Pharmacology and \\ Toxicology, University of Zurich, 8057 Zurich, Switzerland, ${ }^{3}$ Institute of Pharmaceutical Sciences, Swiss Federal Institute of Technology and Collegium \\ Helveticum, 8093 Zurich, Switzerland, and ${ }^{4}$ R. S. Dow Neurobiology Laboratories, Legacy Research, Portland, Oregon 97232
}

The NMDA receptor is thought to play a central role in some forms of neuronal plasticity, including the induction of long-term potentiation. NMDA receptor hypofunction can result in mnemonic impairment and has been implicated in the cognitive symptoms of schizophrenia. The activity of NMDA receptors is controlled by its endogenous coagonist glycine, and a local elevation of glycine levels is expected to enhance NMDA receptor function. Here, we achieved this by the generation of a novel mouse line (CamKII $\alpha \mathrm{Cre} ; \mathrm{Glyt} 1 \mathrm{tm} 1.2 \mathrm{fl} /$ $\mathrm{fl}$ ) with a neuron and forebrain selective disruption of glycine transporter 1 (GlyT1). The mutation led to a significant reduction of GlyT1 and a corresponding reduction of glycine reuptake in forebrain samples, without affecting NMDA receptor expression. NMDA (but not AMPA) receptor-evoked EPSCs recorded in hippocampal slices of mutant mice were 2.5 times of those recorded in littermate controls, suggesting that neuronal GlyT1 normally assumes a specific role in the regulation of NMDA receptor responses. Concomitantly, the mutants were less responsive to phencyclidine than controls. The mutation enhanced aversive Pavlovian conditioning without affecting spontaneous anxiety-like behavior in the elevated plus maze and augmented a form of attentional learning called latent inhibition in three different experimental paradigms: conditioned freezing, conditioned active avoidance, conditioned taste aversion. The CamKII $\alpha$ Cre; Glyt $1 \mathrm{tm} 1.2 \mathrm{fl} / \mathrm{fl}$ mouse model thus suggests that augmentation of forebrain neuronal glycine transmission is promnesic and may also offer an effective therapeutic intervention against the cognitive and attentional impairments characteristic of schizophrenia.

Key words: glycine transporter 1; NMDA receptor; conditional knock-out mice; latent inhibition; selective attention; learning; schizophrenia

\section{Introduction}

According to the glutamate hypothesis of schizophrenia, reduced NMDA receptor (NMRAR) function may contribute to the cognitive impairments of schizophrenia (Farber, 2003; Coyle and Tsai, 2004). Blockade of NMDAR is known to impair the induction of long-term potentiation and learning in animals (Morris et al., 1986; Morris, 1989; Davis et al., 1992). However, NMDAR blockade can also give rise to behavioral dysfunction such as impulsivity (Tonkiss et al., 1988) and psychotic-like behavior: phencyclidine and ketamine (two noncompetitive NMDAR antagonists classified as dissociative anesthetics) are well known psychomimetics (Farber, 2003). In contrast, coagonists of the NMDAR, such as D-serine and glycine, improve cognition and negative symptoms in schizophrenia (Coyle and Tsai, 2004). The

Received Dec. 1, 2005; revised Jan. 12, 2006; accepted Feb. 6, 2006.

This work was supported by Swiss National Science Foundation Grant 3100-066855 and by the National Center of Competence in Research Neural Plasticity and Repair. We thank I. Mansuy for providing the CamKIll $\alpha$-Cre mice. Blastocyst injections were performed at F. Hoffmann-La Roche (Department H. Blüthmann, Basel, Switzerland)

Correspondence should be addressed to Dr. Detlev Boison, Dow Neurobiology Laboratories, Legacy Research, 1225 Northeast 2nd Avenue, Portland, OR 97232. E-mail: dboison@downeurobiology.org.

DOI:10.1523/JNEUROSCI.5120-05.2006

Copyright $\odot 2006$ Society for Neuroscience $\quad$ 0270-6474/06/263169-13\$15.00/0 pharmacological characterization of glycine site ligands was, however, confounded by side effects and insufficient selectivity (Danysz and Parsons, 1998). Thus, the characterization of the glycine site of NMDARs as antipsychotic drug target has remained unsatisfactory.

The action of glycine is essentially terminated by rapid reuptake, mediated by two glycine transporters, glycine transporter 1 (GlyT1) and GlyT2 (Aragon and Lopez-Corcuera, 2005; Eulenburg et al., 2005). Three variants of GlyT1 (GlyT1a, b, and c) are encoded from the same gene. Their expression is restricted to the CNS, distributed widely in the spinal cord, brainstem, cerebellum, and, to a lesser degree, in the cerebral cortex and hippocampus. Autoradiography and immunoelectron microscopy revealed that glial cells around both glycinergic and nonglycinergic neurons contain GlyT1 (Zafra et al., 1995). Novel sequence-specific antibodies, however, have helped to reveal the presence of GlyT1 in glutamatergic synapses of neurons, particularly in the neocortex and hippocampus (Cubelos et al., 2005a). Recently, GlyT1 was also shown to interact with the scaffolding protein PSD-95 (postsynaptic density-95) (Cubelos et al., 2005b). These findings suggest that GlyT1 regulates the concentrations of glycine in the micro-environment of NMDARs. Thus, the selective GlyT1 an- 
tagonist $N$-[3-(4'-fluorophenyl)-3-(4'-phenylphenoxy)] propylsarcosine (NFPS) can enhance NMDAR responses in CA1 pyramidal cells after Schaffer collateral stimulation in acute hippocampal slice preparations (Bergeron et al., 1998) and augment long-term potentiation in the dentate gyrus in vivo (Kinney et al., 2003).

Behavioral analysis of GlyT1 antagonists has thus far failed to yield any convincing promnesic effects, but there is evidence that several GlyT1 inhibitors [NFPS (Kinney et al., 2003), (R)-(N[3-(4'-fluorophenyl)-3-(4'-phenylphenoxy)propyl])sarcosine (ALX 5407) (Lipina et al., 2005), N-methyl-N-[3-[4-trifluoromethyl)phenoxy]-3-phenylpropyl]glycine (ORG 24598) (Le Pen et al., 2003)] may possess antipsychotic property. Similar findings have emerged in mice with a constitutively targeted disruption of the GlyT1 gene. Although homozygous deletion of GlyT1 was lethal (Gomeza et al., 2003), heterozygous mutant mice survived, and these animals showed an enhanced NMDA/AMPA response ratio, a resistance to disruptive effect of amphetamine on prepulse inhibition, and a tendency for improved memory retention (Tsai et al., 2004; Gabernet et al., 2005; Martina et al., 2005).

To molecularly dissect in vivo GlyT1 functions specific to forebrain neurons, from brain-wide mostly astrocytic GlyT1, the selective deletion of GlyT1 in cortical and hippocampal neurons was achieved here by CamKII $\alpha$ Cre-mediated recombination of a conditional loxP-flanked Glytl allele in mice.

\section{Materials and Methods}

\section{Generation of Glyt1tm1.2 mice}

ES cells carrying the conditional Glyt 1 tm 1 allele (Gabernet et al., 2005) were subjected to a second electroporation with an Flp-expression plasmid to remove the frt-flanked neomycin resistance gene. This new Glyt1 allele was designated as Glyt1tm1.2 (see Fig. 1A). Glyt1tm1.2 ES cells were injected into C57BL/6 blastocysts, which were implanted into pseudopregnant mothers. Offspring positive for the Glyt1tm1.2 allele were bred with C57BL/6 mice and selected for germline transmission of the mutation. Finally, a homozygous Glyt $1 \mathrm{tm} 1.2 \mathrm{fl} / \mathrm{fl}$ colony was established and maintained on a pure C57BL/6J background (Glyt1tm1.2Blt).

\section{Genotyping}

PCR primers for genotyping were as follows: o139, 5'-CCTAACCCATGGCC AGGACC-3', Glyt1-specific antisense primer flanking the PGK (phosphoglycerate kinase)-neomycin cassette; o184, 5' -CATCGCCTTCTATCGCCTTCTTGACG-3', sense primer specific for the PGK-neomycin cassette; o228, 5'-GTCAACCTGACTCCTAGCCCTGTACC-3', Glyt1-specific antisense primer 3' to PGK-neomycin-cassette; o232, 5'-AGAAGATCTGAGAGGGTGCATCCC-3', antisense primer specific to the loxP-flanked region; o250, 5'-CCCATGCCCAGATCCATGC-3', sense primer 5' of left loxP-site; o234, 5'TGACAGCAATGCTGTTTCACTGG-3', sense primer specific for Cre-recombinase; o235, 5' -GCATGATCTCCGGTATTGAAACTCC-3', antisense primer specific for Cre-recombinase. The thermocycle of the PCR was 35 cycles at $95^{\circ} \mathrm{C}(15 \mathrm{~s}), 68^{\circ} \mathrm{C}(20 \mathrm{~s})$, and $70^{\circ} \mathrm{C}(90 \mathrm{~s})$.

\section{Glycine uptake}

Adult mice ( 8 weeks of age) were killed by cervical dislocation and hippocampal formation, and the cerebral cortex was rapidly dissected on ice. Tissue was homogenized in 20 volumes of ice-cold $10 \mathrm{~mm}$ Tris, $\mathrm{pH}$ 7.4, $0.32 \mathrm{~m}$ sucrose (four strokes at $1500 \mathrm{rpm}$; Braun Potter S Homogenizer) and centrifuged for $10 \mathrm{~min}$ at $1000 \times \mathrm{g}$. The resulting supernatant was centrifuged for $10 \mathrm{~min}$ at $27,000 \times \mathrm{g}$ to obtain the crude synaptosomal membranes. The membranes were washed twice with $25 \mathrm{~mm}$ HEPES, $\mathrm{pH}$ 7.4, $125 \mathrm{~mm} \mathrm{NaCl}, 5 \mathrm{~mm} \mathrm{KCl}, 2.7 \mathrm{mM} \mathrm{CaCl}_{2}, 1.3 \mathrm{~mm} \mathrm{MgCl}_{2}, 10 \mathrm{~mm}$ glucose (KH buffer) and subjected immediately to $\left[{ }^{3} \mathrm{H}\right]$ glycine uptake studies. For kinetic studies, $150 \mu \mathrm{l}$ of crude synaptosomal membranes $(\sim 100 \mu \mathrm{g}$ of protein) in KH buffer containing increasing concentrations of unlabeled glycine $(5-250 \mu \mathrm{M})$ were incubated for $5 \mathrm{~min}$ at $30^{\circ} \mathrm{C}$ before addition of $50 \mu \mathrm{l}\left[{ }^{3} \mathrm{H}\right]$ glycine $(0.1 \mu \mathrm{M}$ final concentration; $60 \mathrm{Ci} / \mathrm{mmol}$;
PerkinElmer, Emeryville, CA) in $\mathrm{KH}$ buffer. After $15 \mathrm{~min}$ at $30^{\circ} \mathrm{C}$, the uptake was terminated by rapid vacuum filtration using a semiautomatic cell harvester (Skatron Instruments, Lier, Norway). The filters were washed with ice-cold $10 \mathrm{~mm}$ Tris, $\mathrm{pH} 7.4,150 \mathrm{~mm} \mathrm{NaCl}$, dried, and subjected to liquid scintillation counting. Nonspecific $\left[{ }^{3} \mathrm{H}\right]$ glycine uptake was determined in the presence of $10 \mathrm{~mm}$ cold glycine, and GlyT1specific $\left[{ }^{3} \mathrm{H}\right]$ glycine uptake was measured in the presence of $10 \mu \mathrm{M}$ NFPS. $K_{\mathrm{m}}$ and $V_{\max }$ values were determined by nonlinear regression using the GraphPad PRISM 4 software (GraphPad Software, San Diego, CA).

\section{Western blotting}

Tissue of the hippocampus and cortex of adult mice ( 8 weeks of age) was homogenized in $10 \mathrm{vol}$ of $5 \mathrm{~mm}$ Tris/ $\mathrm{HCl}, \mathrm{pH} 7.4$, containing $0.32 \mathrm{M}$ sucrose and centrifuged for $10 \mathrm{~min}$ at $10,000 \times \mathrm{g}$. The resulting supernatant was recentrifuged for $10 \mathrm{~min}$ at $40,000 \times g$ to obtain the crude membrane fraction. The pellet was washed twice in buffer and resuspended at a protein concentration of $5 \mathrm{mg} / \mathrm{ml}$. Aliquots of the membranes with increasing protein content $(2.5,5,7.5,10,15$, and $20 \mu \mathrm{g})$ were incubated for $15 \mathrm{~min}$ at $60^{\circ} \mathrm{C}$ with an equal volume of $125 \mathrm{~mm}$ Tris/HCl, pH 6.8, 20\% glycerol, $0.002 \%$ bromphenol blue, $10 \%$ $\beta$-mercaptoethanol, $4 \%$ SDS, and subjected to SDS-PAGE using 10 or 7.5\% mini-gels (Mini Protean II; Bio-Rad, Hercules, CA). Proteins were transferred onto nitrocellulose membranes using a Trans Blot Mini Cell (Bio-Rad). For immunodetection, the blots were blocked for $1-2 \mathrm{~h}$ in TBST (10 mu Tris/HCl, pH 8, $0.15 \mathrm{M} \mathrm{NaCl}, 0.05 \%$ Tween 20 ) containing $5 \%$ nonfat dry milk at room temperature (RT), followed by incubation with affinity purified GlyT1 antiserum (Gabernet et al., 2005) together with monoclonal actin antibodies (Chemicon, Temecula, CA) overnight at $4^{\circ} \mathrm{C}$ in TBST $/ 5 \%$ blocker. The blots were washed once with $20 \mathrm{~mm}$ Tris, pH 7.5, 60 mm NaCl, 2 mm EDTA, 0.4\% SDS, 0.4\% Triton X-100, 0.4\% deoxycholate, and three times with TBST. Incubation with the appropriate secondary antibodies was performed for $1 \mathrm{~h}$ at RT. After extensive washing, immunoreactivity was detected by chemiluminescence (Super Signal West Pico Chemoluminescence; Pierce, Rockford, IL). Images were captured using a Fuji LAS-1000 plus imaging system (Fujifilm, Tokyo, Japan), and immunoreactive bands were quantified with the AIDA software (version 3.25; Raytest, Pforzheim, Germany). Actin immunoreactivity was used to monitor equal sample loading.

\section{Receptor autoradiography}

Adult mouse brains ( 8 weeks of age) were rapidly dissected and frozen. Slide-mounted parasagittal sections $(12 \mu \mathrm{m})$ were thawed and preincubated four times for $15 \mathrm{~min}$ in $50 \mathrm{~mm}$ Tris- $\mathrm{HCl}, \mathrm{pH} 7.5$, at $4^{\circ} \mathrm{C}$, followed by incubation for $120 \mathrm{~min}$ with a saturating concentration of $\left[{ }^{3} \mathrm{H}\right] \mathrm{L}$ 689,560 (15 nм, 23.6Ci/mmol; Tocris Cookson, Bristol, UK). After washing in buffer (five times for $1 \mathrm{~min}$ ) and a quick dip in distilled water, the sections were dried and exposed to a tritium-sensitive phosphor-imaging screen (Packard Cyclone Storage Phosphor System). Nonspecific $\left[{ }^{3} \mathrm{H}\right] \mathrm{L}-$ 689,560 binding was assessed in parallel by including $1 \mathrm{~mm}$ glycine in the assay buffer. The screen was digitized with a Packard Cyclone Scanner (Packard, Meridian, CT). Specific [ $\left.{ }^{3} \mathrm{H}\right] \mathrm{L}-689,560$ binding was determined using the Optiquant software (Packard) and an autoradiographic $\left[{ }^{3} \mathrm{H}\right]$ micro-scale standard (Amersham Biosciences, Piscataway, NJ) exposed in parallel. The analysis included four animals for each genotype and four to eight sections per animal.

\section{Electrophysiology}

All experiments were performed blinded, and genotypes were determined retrospectively. Brains were taken from postnatal day 21 (P21) to P30 mice and prepared as described previously (Gabernet et al., 2005). Whole-cell patch-clamp techniques were used to study synaptic responses of CA1 pyramidal neurons in response to Schaffer collateral stimulation delivered via a bipolar stimulating electrode $(0.05 \mathrm{~ms}, 1-10$ $\mathrm{V}, 10 \mathrm{~s}$ interstimulus intervals). CA1 pyramidal cells were recorded in the voltage-clamp configuration with 3-6 $\mathrm{M} \Omega$ patch pipettes containing the following (in mM): 130 cesium gluconate, 10 HEPES, $5 \mathrm{NaCl}$, 1 EGTA, 5 ATP-Mg, and 0.5 GTP-Na. AMPA receptor-mediated EPSCs (AMPA EPSCs) were evoked in artificial CSF (ACSF) with picrotoxin $(100 \mu \mathrm{M})$ at $V_{\mathrm{m}}-70 \mathrm{mV}$. The stimulus amplitude was adjusted to evoke average 
current amplitude of $\sim 100 \mathrm{pA}$. AMPA EPSCs were abolished in ACSF containing 1,2,3,4-tetrahydro-6-nitro-2,3-dioxo-benzo[f] quinoxaline7 -sulfonamide (NBQX; $20 \mu \mathrm{M})$. Next, the potential of the cell was clamped at $+40 \mathrm{mV}$ to release the $\mathrm{Mg}^{2+}$ block and permit the recording of isolated NMDA receptor-mediated EPSCs (NMDA EPSCs). In some experiments, the NMDA receptor blocker 3- $((R)$-2-carboxypiperazine4-yl)-propyl-1-phosphonic acid (R-CPP), $20 \mu \mathrm{M}$ was added at the end of the recording to ensure that all outward currents were NMDA receptor mediated. AMPA receptor-mediated miniature EPSC events (AMPA mEPSCs) were recorded at $V_{\mathrm{m}}-70 \mathrm{mV}$ in normal ACSF containing picrotoxin $(100 \mu \mathrm{M})$, tetrodotoxin (TTX; $1 \mu \mathrm{M})$, and R-CPP $(20 \mu \mathrm{M})$ with patch pipettes containing the following (in $\mathrm{mm}$ ): 130 potassium gluconate, 10 HEPES, 1 EGTA, $5 \mathrm{NaCl}, 5$ ATP-Mg, and 0.5 GTP-Na. Voltage-clamp recordings were obtained with an Axopatch 200B (Molecular Devices, Foster City, CA) amplifier. Signals were sampled at 2-5 $\mathrm{kHz}$ and acquired and analyzed using IgorPro (Wavemetrics, Lake Oswego, OR) software. The NMDA/AMPA ratio was given as the ratio of the NMDA peak amplitude to the AMPA peak amplitude (INMDA at $+40 \mathrm{mV}$ /IAMPA at $-70 \mathrm{mV}$ ). AMPA mEPSCs were analyzed using Mini Analysis Program (Synaptosoft, Decatur, GA). Average values are expressed as mean \pm SEM. Student's $t$ test was used for statistical comparisons. Picrotoxin, NBQX, R-CPP, and TTX were from Tocris Cookson (Bristol, UK).

\section{Behavioral assays}

All behavioral experiments were conducted in the Laboratory of Behavioral Neurobiology, Schwerzenbach, which maintained eight independent CamKII $\alpha$ Cre:Glyt $1 \mathrm{tm} 1.2 \mathrm{fl} / \mathrm{fl} \times$ Glyt $1 \mathrm{tm} 1.2 \mathrm{fl} / \mathrm{f}$ breeding pairs. The offspring were sexed and genotyped at 3 weeks of age by standard PCR. CamKII $\alpha$ Cre:Glyt 1 tm1.2fl/fl (hereafter simply referred to as "mutant") mice were compared with Glyt $1 \mathrm{tm} 1.2 \mathrm{fl} / \mathrm{fl}$ littermate controls. Mice were caged in groups of five or less and kept under temperature-controlled $\left(21^{\circ} \mathrm{C}\right)$ and humidity-controlled $(55 \%)$ conditions with a $12 \mathrm{~h}$ reversed light/dark cycle (lights on at 8:00 P.M.). They were maintained under ad libitum food and water unless stated otherwise, and testing always took place in the dark phase of the light/dark cycle.

Three separate cohorts of adult mice were used in the behavioral experiments, and the mice were all at the age of 11-12 weeks at the beginning of behavioral testing. The first consisted of 15 mutant and 18 control female mice. They were all tested in experiment 1 before being further evaluated in experiments 2 and 3. One control mouse became ill after experiment 1 , and one mutant mouse also appeared unfit after experiment 2; these mice were not included in the subsequent tests. The second cohort, comprising 17 mutant and 13 control female mice, was used in experiment 4 . These animals were used previously in another operant conditioning experiment (not reported here). Prior pre-exposed (PE) and non-pre-exposed (nPE) experiences in preceding tests were always counterbalanced. The third cohort comprised nine mutant and eight control male mice that had been used previously in two pilot tests of associative learning. All manipulations described here had been approved previously by the Cantonal Veterinary Office of Zurich; they conformed to the ethical standards required by the Swiss Act and Ordinance on Animal Protection and the European Council Directive 86/609/EEC.

All behavioral data were subjected to parametric ANOVA of the appropriate design conducted using SPSS (Chicago, IL) for Windows (release 13.0). Data interpretation was further assisted by a priori contrast comparison, Fisher's least significant difference (LSD) post hoc comparisons and the use of restricted ANOVAs whenever appropriate.

Experiment 1: elevated plus maze. The expression of spontaneous anxiety-like behavior was assessed in this test, and the animals were behaviorally naive at the time of testing. The maze consisted of two exposed and two enclosed arms joined to a central square platform. Its construction has been described fully (Yee et al., 2004). Each test session began by placing the animal into the central area facing one of the open arms. It was then left to explore freely for $5 \mathrm{~min}$ before being removed and returned to the home cage. A digital camera was mounted above the maze. Images were captured at a rate of $5 \mathrm{~Hz}$ and transmitted to a personal computer running the Ethovision tracking system (Noldus Technology,
Wageningen, The Netherlands). Two anxiety-related measures were computed: (1) percentage of time spent in the open arms [open/(open + closed) $\times 100 \%$; (2) percentage of the number of entries made to the open arms [open/(open + closed $) \times 100 \%]$. In addition, the total mobility score (defined as the cumulative spatial displacement of the animal's center of gravity, and expressed in centimeters) was computed.

Experiment 2: latent inhibition in the conditioned freezing paradigm. This test allows the evaluation of Pavlovian conditioning. We adopted a design that further allowed the assessment of latent inhibition effect, whereby pre-exposures of the to-be-conditioned conditioned stimulus (CS) before conditioning retard the development and subsequent expression of the conditioned response. In this and all subsequent latent inhibition experiments, we adopted a design that, in general, tended to generate weak or only marginal latent inhibition effect in the control. This approach is common for the demonstration of treatment expected to enhance the latent inhibition effect (Feldon and Weiner, 1991).

In the conditioned freezing experiment, the apparatus comprised eight conditioning chambers as described previously (Meyer et al., 2005). All chambers were equipped with a grid floor made of stainless-steel rods spaced at $10 \mathrm{~mm}$ intervals, and through which scrambled electric shocks [unconditioned stimulus (US)] could be delivered (model E13-14; Coulbourn Instruments, Allentown, PA). The CS was an $86 \mathrm{~dB}_{\mathrm{A}}$ tone provided by a sonalert (model SC628; Mallory, Indianapolis, IN). A digital camera was mounted $30 \mathrm{~cm}$ directly above the area of interest in each chamber, which captured images at a rate of $1 \mathrm{~Hz}$. Successive frames were compared to evaluate freezing behavior (Richmond et al., 1998).

The test procedures of the latent inhibition (LI) test consisted of four phases: Pre-exposure, conditioning, context-test, and CS-test. Within each genotype group, the animals were randomly allocated to either the $\mathrm{PE}$ condition (mutant/PE, $n=8$; control/PE, $n=9$ ) or the $\mathrm{nPE}$ condition (mutant $/ \mathrm{nPE}, n=7$; control/nPE, $n=8$ ). PE subjects received 40 presentations of a $30 \mathrm{~s}$ tone CS at a variable interstimulus interval of $40 \pm$ $30 \mathrm{~s} ; \mathrm{nPE}$ subjects were confined to the chamber for an equivalent period of time. Conditioning commenced immediately at the end of preexposure without removing the animals from the chambers. Conditioning comprised three discrete trials of CS-US pairing. Each trial began with the $30 \mathrm{~s}$ tone stimulus (identical to the one used during preexposure) followed immediately by the delivery of a $1 \mathrm{~s}$ foot shock set at $0.25 \mathrm{~mA}$. Each trial was preceded and followed by a 180 s interval. The test of contextual freezing took place $24 \mathrm{~h}$ later when the subjects were returned to the same chambers and observed for a period of $480 \mathrm{~s}$ in the absence of any discrete stimulus. The test of conditioned response to the tone CS was conducted another $24 \mathrm{~h}$ later, when the animals were returned to the chambers. After a $180 \mathrm{~s}$ acclimatization period, the tone CS was turned on for $480 \mathrm{~s}$; freezing behavior to the tone stimulus during this period was evaluated.

Experiment 3: latent inhibition in the conditioned active avoidance paradigm. This task captures both elements of classical and instrumental conditioning, in which the animals learned to perform a specific operant act in response to a noise stimulus to avoid the delivery of an aversive foot shock. Again, we adopted a design to allow the assessment of latent inhibition in this learning paradigm.

The apparatus consisted of four identical two-way shuttle boxes (model H10-11M-SC; Coulbourn Instruments). The internal dimensions of each box were $35.5 \times 18 \times 32.5 \mathrm{~cm}$. The box was separated into two identical compartments by an aluminum wall with an interconnecting opening $(6.5 \times 8 \mathrm{~cm})$, allowing the animal to move freely from one compartment to the other (i.e., a shuttle response). The grid floor was made of stainless-steel rods (diameter, $0.4 \mathrm{~cm}$; spaced, $0.7 \mathrm{~cm}$ ) and connected to a constant current shock generator (model H10-1M-XX-SF; Coulbourn Instruments). Through the grids, electric shocks $(0.3 \mathrm{~mA})$ could be delivered. The CS was an $83 \mathrm{~dB}_{\mathrm{A}}$ white noise. Shuttle response was detected by a series of photocells (H20-95X; Coulbourn Instruments) mounted on the side of both shuttle compartments.

The animals were subdivided into two conditions, $\mathrm{PE}$ and nPE, with their pre-exposure experience in the preceding LI experiment counterbalanced (mutant/PE, $n=8$; control/PE, $n=9$; mutant/nPE, $n=7$; control/nPE, $n=8)$.

On the first day, the animals were placed in the shuttle chambers: PE 
animals received 50 presentations of a $5 \mathrm{~s}$ white noise stimulus $\left(83 \mathrm{~dB}_{\mathrm{A}}\right.$ in magnitude against a background noise of $63 \mathrm{~dB}_{\mathrm{A}}$ ) presented at a variable interstimulus-interval (mean of $40 \mathrm{~s}$, ranging from 25 to $55 \mathrm{~s}$ ); the nPE animals spent an equivalent period of time in the chamber without any stimulus presentation.

On the second day, the animals underwent 100 conditioned avoidance trials administered at variable intertrial intervals (mean of $40 \mathrm{~s}$, ranging from 25 to $55 \mathrm{~s}$ ). A trial began with the onset of the noise CS. If the animal shuttled within $5 \mathrm{~s}$ of CS onset, the CS was terminated and the animal avoided the electric shock on that trial. Avoidance failure led immediately to an electric foot shock presented in coincidence to the CS. This could last for a maximum of $2 \mathrm{~s}$ but could be terminated by a shuttle response during this period (i.e., an escape response). To index conditioned avoidance learning, the mean latency to response across successive 10-trial blocks was submitted to statistical analysis. The latency was transformed to speed (1/s) for the purpose of analysis.

Experiment 4: latent inhibition in the conditioned taste aversion paradigm. This paradigm is a one-trial classical conditioning paradigm, in which a single pairing of a taste CS and gastric malaise leads to a lasting aversion to the taste. However, the efficacy to acquire the conditioned aversion would be reduced if the subjects experienced the same taste CS without any consequence. This effect of prior CS exposures constitutes another demonstration of the latent inhibition effect and was also assessed here.

Throughout the experiment, the animals were housed singly in Makrolon cages $(1291 \mathrm{H}$, Eurostandard type III, H:425 $\times 266 \times 185 \mathrm{~mm}$; Tecniplast S.p.a., Milan, Italy). The two drinking tubes were made from $15 \mathrm{ml}$ polypropylene test tubes (Cellstars; Greiner Bio-One, Frickenhausen, Germany) equipped with an air-tight screwed top. An opening, $2.5 \mathrm{~mm}$ in diameter, was made in the bottom of the tubes to allow access to the liquid within the animals. Two acrylic rings $(20 \mathrm{~mm}$ in inner diameter) were affixed to the metal grids of the cage to provide a stable anchor for the drinking tubes. When the tubes were inserted lumen of the rings, the two drinking holes were $40 \mathrm{~mm}$ apart, at a level of $\sim 50 \mathrm{~mm}$ above the cage floor. With this arrangement of the tubes, the animals could easily switch drinking form one tube or the other. The liquid consumption of a drinking tube was assessed by calculating the weight difference of each drinking tube before and after a drinking session.

A 10\% (w/v) D-sucrose solution served as the taste CS. Gastric malaise, induced by systemic injection of lithium chloride $(\mathrm{LiCl})$ solution, served as the US. LiCl (Sigma-Aldrich, Buchs, Switzerland) was dissolved in $0.9 \% \mathrm{NaCl}$ solution to a final concentration of $0.25 \mathrm{M}$ on the day of conditioning. The volume of $\mathrm{LiCl}$ injection was $2 \% \mathrm{v} / \mathrm{w}$ of the body weight and was administered via the intraperitoneal route at the end of the first drinking period on the conditioning day.

After habituation to single housing for $2 \mathrm{~d}$, access to water was gradually restricted over a $5 \mathrm{~d}$ period as described by Meyer et al. (2004). On the last of these $5 \mathrm{~d}$, the water restriction was reduced to $1 \mathrm{~h}$. Thereafter and until the end of experiment, the animals were allowed two 30 min drinking periods per day, separated by $4 \mathrm{~h}$. Two drinking tubes were inserted into the cage in each of the two drinking periods, and the animals could freely consume liquid from either tube. Manipulations of the content of the drinking tubes were also conducted in the first drinking period of a day (see below). In the second period, both tubes were always filled with plain tap water.

As described below, the experimental procedure consisted of four phases: baseline, pre-exposure, conditioning, and test of conditioned aversion.

Baseline. Over the first $3 \mathrm{~d}$, both tubes contained water in both drinking periods to acclimatize the animals to drinking from the water tubes. The allocation of subjects into PE (nine mutant and seven control mice) and nPE (eight mutant and six control mice) conditions was counterbalanced according to the animals' performance in the first drinking period across the three baseline days.

Pre-exposure. On the next day, PE subjects were provided with $10 \%$ (w/v) D-sucrose solution in both tubes during the first drinking period. nPE subjects had access to water in both tubes during the first drinking period.

Conditioning. The next day, $\mathrm{PE}$ and nPE subjects were provided with sucrose solution in both tubes during the first drinking period. All animals received an $\mathrm{LiCl}$ injection 5 min afterward.

Test. The next day, conditioned taste aversion to the sucrose solution was measured in a two-choice test in which one tube contained sucrose solution and the other water, thus allowing the animals a free choice between the two.

Experiment 5: locomotor reaction to systemic amphetamine and phencyclidine. The apparatus consisted of four open-field white wooden square arenas $(40 \times 40 \mathrm{~cm})$ as described previously (Hauser et al., 2005). Amphetamine $(2.5 \mathrm{mg} / \mathrm{kg})$, phencyclidine $(5 \mathrm{mg} / \mathrm{kg})$, or vehicle saline solution $(0.9 \% \mathrm{NaCl})$ was administered via the intraperitoneal route (at an injection volume of $5 \mathrm{ml} / \mathrm{kg}$ ) immediately before testing. The animals were observed for $2 \mathrm{~h}$. A digital camera mounted above the open fields captured images at a rate of $5 \mathrm{~Hz}$ and transmitted them to a personal computer running the Ethovision tracking system (Noldus Technology), which calculated a mobility score defined as distance traveled per bin at successive 5 min bins. A square-root transformation was performed before statistical analysis.

\section{Results}

\section{Generation of CamKII $\alpha$ Cre:Glyt $1 \mathrm{tm} 1.2 \mathrm{fl} / \mathrm{fl}$ mice}

To achieve forebrain-specific neuronal recombination of the floxed Glyt1 allele, conditional Glyt1 knock-out mice (Glyt1tm1.2fl/fl) (Fig. 1A) were generated and bred with CamKII $\alpha$ Cre2834 mice. CamKII $\alpha$ Cre2834 mice were produced by pronuclear injection of a construct carrying an $8.5 \mathrm{~kb}$ fragment of the CamKII $\alpha$ promoter (Mayford et al., 1996) fused to the Cre gene. The spatiotemporal expression pattern of the CamKII $\alpha$ Cre2834 transgene has been described previously (Schweizer et al., 2003). According to studies of CamKII $\alpha$ Cre2834 expression in Z/AP reporter mice and in floxed $\gamma_{2}-\mathrm{GABA}_{\mathrm{A}}$ receptor knock-out mice, CamKII $\alpha$ Cre2834induced recombination was first detected in the hippocampus at P17 and then gradually increased to near adult levels by P34, concomitant with a spread to other forebrain regions (Schweizer et al., 2003). Whereas the onset and final pattern of recombination in CamKII $\alpha$ Cre2834 mice was very similar to that observed in T29-1 CamKII $\alpha$ Cre mice (Tsien et al., 1996), recombination of the floxed $\gamma_{2}-\mathrm{GABA}_{\mathrm{A}}$ receptor locus by the T29-1 transgene progressed more slowly than recombination by the CamKII $\alpha$ Cre2834 transgene (Schweizer et al., 2003). Thus, CamKII $\alpha$ Cre2834 mice constitute an ideal tool to study Cremediated GlyT1 ablation in the hippocampus after the third postnatal week and in the forebrain of adult mice.

Both parent lines were on a pure C57BL/6J background, and additional breeding gave rise to CamKII $\alpha$ Cre:Glyt $1 \mathrm{tm} 1.2 \mathrm{fl} / \mathrm{fl}$ mice. The mouse colony was maintained by breeding CamKII $\alpha$ Cre: Glyt1tm1.2fl/fl mice with Glyt1tm1.2fl/fl mice, maintaining the colony heterozygous for the Cre-gene. Therefore, we obtained mixed litters of CamKII $\alpha$ Cre:Glyt1tm1.2fl/fl and Glyt1tm1.2fl/fl mice in a 1:1 ratio, the latter genotype being used as control. Genotypes were determined by PCR analyses of mouse-tail biopsies (Fig. $1 A, B$ ). Both CamKII $\alpha$ Cre:Glyt1tm1.2fl/fl mice and Glyt1tm1.2fl/fl mice were characterized by the lack of the neomycine resistance cassette, which was not amplified using primers o184/o139, whereas a $450 \mathrm{bp}$ amplification product was obtained using DNA from Glyt1tm1 mice (Fig. 1). The presence of the loxP flanked region was verified in all three genotypes (Glyt1tm1, CamKII $\alpha$ Cre:Glyt1tm1.2fl/fl, and Glyt $1 \mathrm{tm} 1.2 \mathrm{fl} / \mathrm{fl}$ ) by a $1050 \mathrm{bp}$ amplification product using primers o232/o250 (Fig. 1). In tail biopsies from these mice, recombination of the loxP sites and deletion of the intervening sequence was never observed (primers o228/250) (Fig. 1). However, when DNA isolated from the forebrain of CamKII $\alpha$ Cre:Glyt1tm1.2fl/fl mice was amplified with primers o228/o250, a characteristic 500 bp band resulted, indicative of a forebrain-specific deletion of the loxP-flanked region (Fig. 1). These mice (tail and forebrain DNA) were also characterized by a $650 \mathrm{bp}$ amplification product from primers o234/o235, indica- 
A

\section{Glyt1tm1 allele}

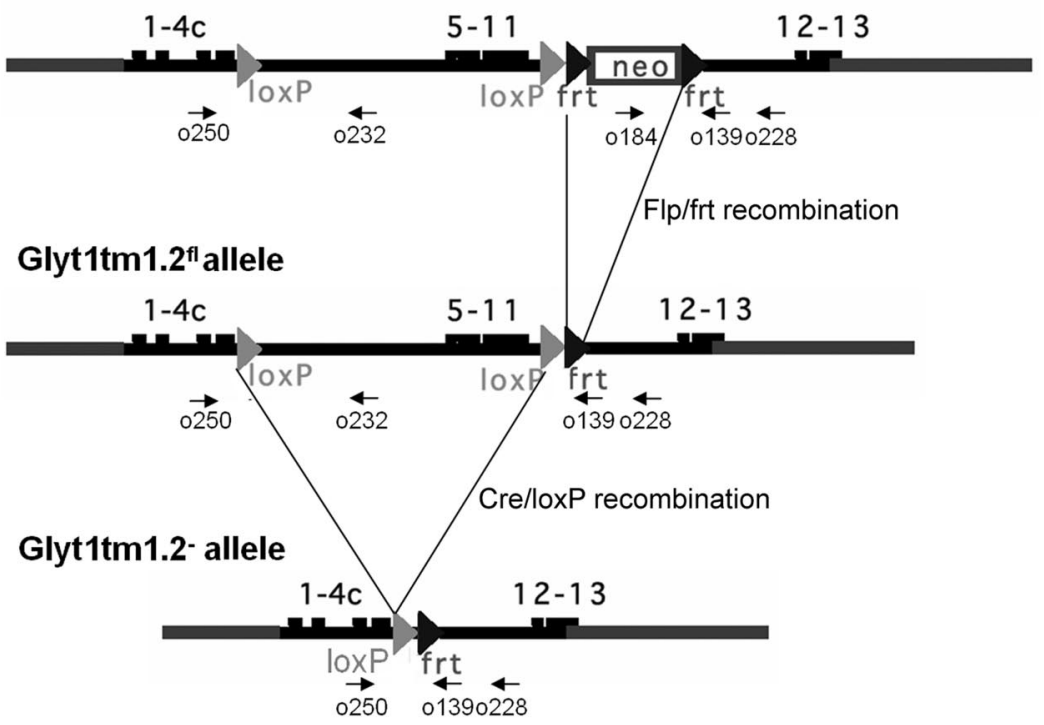

PCR Analysis

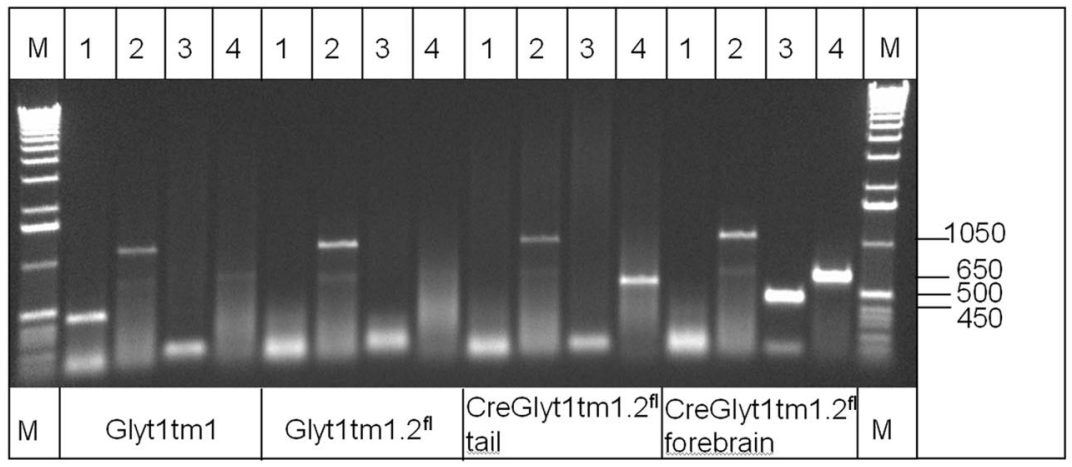

Figure 1. Flp- and Cre-mediated recombination of the Glyt1tm1 allele. $\boldsymbol{A}$, Scheme of Glyt1 loci (not to scale). Top, Glyt1tm1 allele representing the original homologous recombination. Middle, Flp/frt recombination of Glyt1tm1 gives rise to the conditional Glyt1tm1.2fl allele. Bottom, Cre/loxP recombination gives rise to the recombinant Glyt1tm1.2- allele. Numbered exons are shown as black bars, frt and loxP recombination sites are shown as triangles, and the neomycine resistance gene (neo) is shown as a box. PCR primers are indicated by arrows. $\boldsymbol{B}, \mathrm{PCR}$ analysis of mutant Glyt1 alleles. DNA was prepared from tail biopsies of Glyt1tm1, Glyt1tm1.2fl/fl, and CamKII $\alpha$ Cre:Glyt1tm1.2fl/fl (CreGlyt1tm1.2fl tail) mice and from the forebrain taken from CamKIl $\alpha$ Cre: Glyt1tm1.2fl/fl (CreGlyt1tm1.2fl forebrain) mice. PCR primers (top row) were as follows: lane 1, neo-specific primers 0184/0139; lane 2, primers $0250 / 0232$ for intact loxP-flanked region; lane 3, primers $0250 / 0232$ specific for Cre-mediated deletion of loxP flanked region; lane 4, primers 0234/0235 specific for the presence of CamKIl $\alpha$ Cre; M, $1 \mathrm{~kb}$ ladder. The numbers at the right indicate base pairs.

tive for the presence of CamKII $\alpha$ Cre. Because CamKII $\alpha$ Cre is selectively expressed in neurons (Mayford et al., 1996), the o228/o250dependent 500 bp amplification product from forebrain samples (Fig. $1 B$ ) most likely results from neuronal recombination of the Glyt $1 \mathrm{tm} 1.2 \mathrm{fl}$ allele. The presence of the o232/o250-dependent 1050 bp amplification product from forebrain samples (Fig. $1 B$ ) is indicative of a non-recombined Glyt $1 \mathrm{tm} 1.2 \mathrm{fl}$ allele, most likely derived from astrocytes or other non-neuronal cells. The PCR analysis presented here thus documents Cre-mediated recombination in the forebrain of CamKII $\alpha$ Cre:Glyt1tm1.2fl/fl mice.

CamKII $\alpha$ Cre:Glyt $1 \mathrm{tm} 1.2 \mathrm{fl} / \mathrm{fl}$ mice display reductions of GlyT1 levels and glycine uptake but no changes in NMDA receptor expression in the forebrain

To assess the consequences of a forebrain-specific neuronal disruption of the Glyt1 gene on GlyT1 protein expression, mem- brane preparations of hippocampus/cortex of adult ( 8 weeks of age) wild-type and mutant mice were analyzed by Western blotting using GlyT1-selective antibodies. In adult animals CamKII $\alpha$ Cre2834mediated recombination in the forebrain is considered to be complete (Schweizer et al., 2003). GlyT1 protein levels in mutants were reduced by $30 \pm 8 \%$, indicating a significant neuronal pool of GlyT1 (Fig. $2 B)$. Functionally, the reduced GlyT1 protein level resulted in a $35 \pm 4 \%$ decrease of GlyT1-specific $\left[{ }^{3} \mathrm{H}\right]$ glycine uptake as determined in synaptosomal membrane preparations from hippocampus/cortex in the presence and absence of the GlyT1selective inhibitor NFPS (Fig. 2 A). Saturation experiments revealed a significant reduction of the $V_{\max }$ value in mutants from $26 \pm 1$ to $17 \pm 1 \mathrm{pmol} / \mathrm{min} / \mathrm{mg}$ protein with no significant change in the $K_{\mathrm{m}}$ value (wild type, $26 \pm 4 \mu \mathrm{M}$; mutant, $21 \pm 1$ $\mu \mathrm{M})$. These results demonstrate that the neuron-specific disruption of GlyT1 in the forebrain translates into a severe deficit of NFPS-specific glycine uptake.

The diminished GlyT1-selective glycine uptake suggests elevated extracellular glycine levels in mutant mice, which may affect NMDA receptor expression. Therefore, potential changes in NMDA receptor expression were analyzed with a high spatial resolution by receptor autoradiography in the hippocampal formation using the glycine site antagonist $\left[{ }^{3} \mathrm{H}\right] \mathrm{L}-689,560$. No significant difference in $\left[{ }^{3} \mathrm{H}\right] \mathrm{L}-689,560$ binding was detected in various areas of the hippocampal formation (Fig. 2C).

\section{Enhancement of hippocampal NMDA receptor function by disruption of GlyT1 in forebrain neurons}

The lack of GlyT1 in hippocampal neurons was expected to lead to an increase of glycine at glutamatergic synapses and to an enhancement of NMDA receptor function. The experiments described here were performed on slightly older brain slices (P21-P30) compared with our previous publication (P17-P24) (Gabernet et al., 2005) to ensure that CamKII $\alpha$ Cre2834-mediated recombination in the hippocampus (beginning from P17 onwards) had taken place. The ratio of NMDA to AMPA-mediated currents was chosen to assess the modification of NMDA receptor function in CamKII $\alpha$ Cre:Glyt1tm1.2fl/fl mice. The average peak amplitude of evoked AMPA EPSCs in CamKII $\alpha$ Cre:Glyt1tm1.2fl/fl and Glyt1tm1.2fl/fl mice amounted to $85.9 \pm 16.4 \mathrm{pA}(n=6)$ in Glyt1tm1.2fl/fl mice and to $90.6 \pm 11.1 \mathrm{pA}(n=8)$ in CamKII $\alpha$ Cre:Glyt1tm1.2fl/fl mice (Fig. 3A). After blocking the AMPA EPSCs by the addition of NBQX, NMDA EPSCs were isolated in the same cells at $V_{\mathrm{m}}+40 \mathrm{mV}$ and displayed average peak amplitude of $44.5 \pm 13.0 \mathrm{pA}(n=6)$ in Glyt $1 \mathrm{tm} 1.2 \mathrm{fl} / \mathrm{fl}$ mice and $81.5 \pm 7.4 \mathrm{pA}(n=8)$ in CamKII $\alpha$ Cre:Glyt1tm1.2fl/fl mice (Fig. 3A). The NMDA component of EPSCs was completely 
blocked by the addition of R-CPP (data not shown) as described previously (Gabernet et al., 2005). The ratio of the peak amplitudes of NMDA to AMPA-mediated EPSCs amounted to $0.46 \pm 0.06$ in Glyt $1 \mathrm{tm} 1.2 \mathrm{fl} / \mathrm{fl}$ mice $(n=6)$ and $1.01 \pm$ 0.16 in CamKII $\alpha$ Cre:Glyt $1 \mathrm{tm} 1.2 \mathrm{fl} / \mathrm{fl}$ mice $(n=8)$, corresponding to a 2.15 -fold enhancement of the NMDA/AMPA response ratio in the mutants $(p<0.05)$. To exclude the possibility that the increased NMDA/AMPA ratio is attributable to a reduction of the AMPA response in the mutants, the kinetics of the NMDA and AMPA components of EPSCs was compared and found not to differ significantly between genotypes. The properties of AMPA mEPSCs, which reflect the postsynaptic response to the presynaptic release of single vesicles, were recorded at $V_{\mathrm{m}}-70 \mathrm{mV}$ in the presence of TTX, $\mathrm{R}-\mathrm{CPP}$, and picrotoxin. Average AMPA EPSCs decay time constants were $13.2 \pm$ $1.1 \mathrm{~ms}(n=6)$ (Glyt $1 \mathrm{tm} 1.2 \mathrm{fl} / \mathrm{fl})$ and $15.6 \pm 2.0 \mathrm{~ms}(n=8)$ (CamKII $\alpha$ Cre: Glyt $1 \mathrm{tm} 1.2 \mathrm{fl} / \mathrm{fl})$. Likewise, the rise times of AMPA EPSCs were similar $(2.0 \pm 0.2 \mathrm{~ms}$ for the control and $2.0 \pm 0.1 \mathrm{~ms}$ for the mutants). The average NMDA EPSC decay time constant was $105.2 \pm 18.4 \mathrm{~ms}$ $(n=6)($ Glyt1tm1.2fl/fl) and $86.4 \pm 8.7$ ms $(n=8)$ (CamKII $\alpha$ Cre:Glyt $1 \mathrm{tm} 1.2 \mathrm{fl} /$ $\mathrm{fl})$, whereas the rise times were $4.2 \pm 0.4$ $\mathrm{ms}$ and $4.2 \pm 0.2 \mathrm{~ms}$, respectively (Fig. $3 B$ ). We conclude that the NMDA receptor activity is enhanced in CamKII $\alpha$ Cre: Glyt1tm1.2fl/fl mice, whereas kinetic properties of AMPA and NMDA EPSCs remained unaltered.

\section{Elevated plus maze behavior remains unaltered in the \\ CamKII $\alpha$ Cre:Glyt1tm1.2fl/fl mice}

For the interpretation of data derived from the subsequent aversive conditioning paradigms, it is essential to ascertain whether the mutation had any effects on unconditioned anxiety-like behavior and spontaneous locomotor activity. The elevated plus maze test was therefore conducted in a cohort of adult mice (15 mutants and 19 littermate controls) when the animals were totally behavioral naive.

The measures of percentage of open arm entries and percentage of time spent in open arms conformed closely to each other and suggested that the expression of anxiety-like behavior as indexed by the animals' reluctance to venture into the open arms was highly comparable between the mutant and control mice. The mutant and control mice spent, respectively, $29.0 \pm 6.5$ and $24.9 \pm 3.5 \%$ time in the open arms. Based on the total number of arm entries, the mean percentage of entries into the open arms by the mutant and control mice are $40.0 \pm 5.5$ and $35.4 \pm 3.7 \%$, respectively. Examination of locomotion as measured by total
B
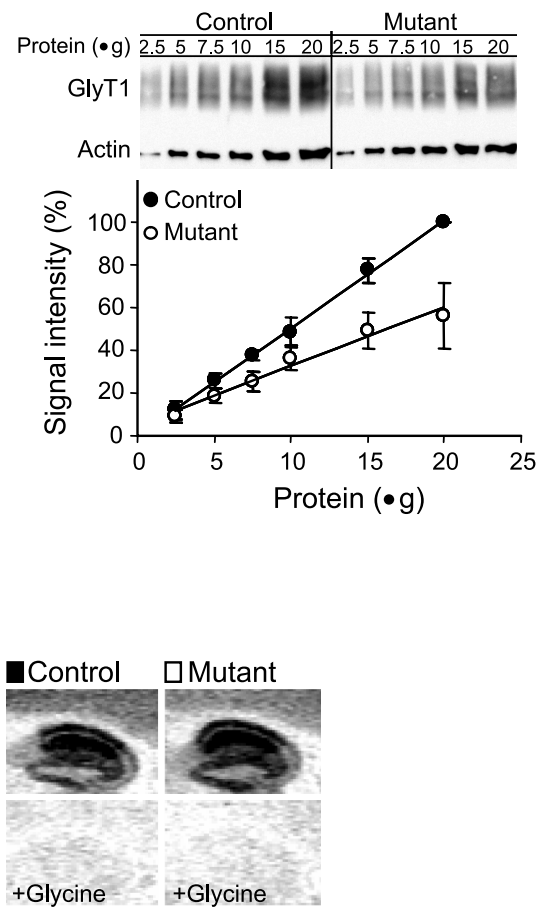

Figure 2. Reduction of GlyT1 and NFPS-specific $\left[{ }^{3} \mathrm{H}\right]$ glycine uptake but not of NMDA receptor in mutant mice. $\boldsymbol{A}$, Reduced glycine uptake in mutant mice. Glycine transport in synaptosomal membrane preparations from hippocampus/cortex of mutant and wild-type mice was analyzed by measuring NFPS-specific $\left[{ }^{3} \mathrm{H}\right]$ glycine uptake at different glycine concentrations. The $V_{\max }$ value was reduced in mutants from $26 \pm 1 \mathrm{pmol} / \mathrm{min} / \mathrm{mg}$ (control) to $17 \pm 1 \mathrm{pmol} / \mathrm{min} / \mathrm{mg}$ protein with no change in the $K_{\mathrm{m}}$ value (control, $26 \pm 4 \mu \mathrm{m}$; mutant, $21 \pm 1 \mu \mathrm{m}$ ). Data represent the mean \pm SD of three independent experiments. $\boldsymbol{B}$, Reduced GlyT1 levels in mutant mice. Expression levels of GlyT1 in wild-type and mutant mice were analyzed by probing Western blots containing increasing protein concentrations from hippocampus/cortex with GlyT1-specific antiserum. The top panels depict representative Western blots probed with GlyT1 antibodies and simultaneously with actin antibodies to control for equal sample loading. The bottom panels show the quantification of the Western blots normalized to the GlyT1 signal at $20 \mu \mathrm{g}$ in control mice (100\%). Data represent the mean \pm SD of four experiments. C, Unaltered $\left[{ }^{3} \mathrm{H}\right] \mathrm{L}-689,560$ binding to NMDA receptors in hippocampal formation in mutant mice. The level of NMDA receptors in the hippocampal formations was assessed by radioligand binding to brain sections and autoradiography using [ $\left.{ }^{3} \mathrm{H}\right] \mathrm{L}-689,560$, an antagonist of the glycine site. Results are given as mean \pm SD of four mice for each genotype. Inset, Representative autoradiograms depicting $\left[{ }^{3} \mathrm{H}\right] \mathrm{L}-689,560$ binding to the hippocampal formation in radiatum of CA1; CA1lac, stratum lacunosum moleculare of CA1; CA3ori, stratum oriens of CA3; CA3pyr, stratum pyramidale of $C A 3$; CA3rad, stratum radiatum of CA3; DGgcl, stratum granulosum dentate gyrus; DGpol, stratum polymorphe of dentate gyrus; DGmol, stratum moleculare of dentate gyrus.

distance traversed in the maze also indicated that the two groups behaved similarly to each other (mutant, $907.4 \pm 62.6 \mathrm{~cm}$; control, $942.2 \pm 29.1 \mathrm{~cm}$ ). Separate one-way ANOVAs of the three variables failed to yield any significant group effect (all $F$ values $<1)$.

CamKII $\alpha$ Cre:Glyt $1 \mathrm{tm} 1.2 \mathrm{fl} / \mathrm{fl}$ mice show enhanced expression of conditioned tone-freezing with an augmentation of the latent inhibition effect

To investigate the consequences of the forebrain and neuronselective disruption of GlyT1 on associative learning and its con- 
A AMPA and NMDA

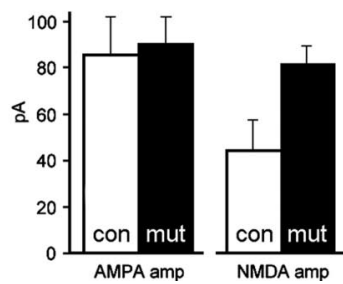

$\mathrm{B}$ AMPA EPSCs Decay Time Constant

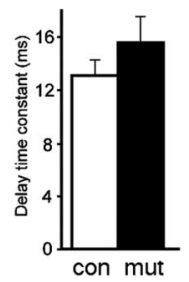

AMPA EPSCs Rise time

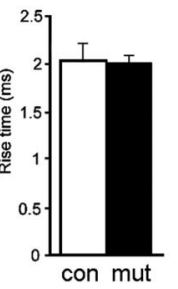

NMDA EPSCs Decay Time Constant

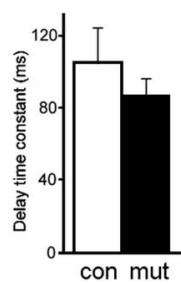

NMDA EPSCs Rise Time

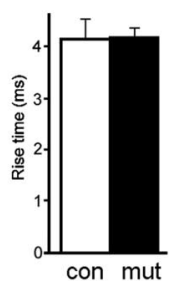

Figure 3. AMPA/NMDA EPSCs peak amplitude and mEPSCs properties of hippocampal CA1 pyramidal cells of CamKIl $\alpha$ Cre: Glyt1tm1.2fl/fl mice. A, Averaged EPSCs peak amplitude (amp) in CA1 pyramidal neurons of Glyt1tm1.2fl/fl (con) and CamKIl $\alpha$ Cre:Glyt1tm1.2fl/fl (mut) mice. B, AMPA and NMDA mEPSCs properties are not affected in CamKII $\alpha$ Cre:Glyt1tm1.2fl/fl cells. Average AMPA and NMDA mEPSC rise time and decay time constants from Glyt1tm1.2fl/fl (con) and CamKIll $\alpha$ Cre: Glyt1tm1.2fl/fl (mut) cells indicating no significant change in the mEPSC kinetics (two-tailed independent Student's $t$ test).

to the conditioning chamber. The tone was presented 3 min into the session and remained continuously for $8 \mathrm{~min}$ (Fig. $4 C)$. In the $3 \mathrm{~min}$ before CS onset, freezing was generally low and the mutant and control mice did not differ in their overall level of freezing. Analysis over the $8 \mathrm{~min}$ CS period revealed a significant interaction between genotype and pre-exposure $\left(F_{(1,28)}\right.$ $=5.41 ; p<0.05)$. Fisher's LSD comparisons confirmed the significant presence of LI in the mutant $(p<0.05)$ but not in the control. It is apparent that the enhancement of the LI effect seen in the mutant was achieved via increased tone-freezing in the $\mathrm{nPE}$ condition and decreased tonefreezing in the PE condition, compared with control mice.

trol by selective attention, we compared mutant $(n=15)$ and littermate controls $(n=17)$ in a conditioned tone-freezing paradigm that included the assessment of LI. LI is demonstrated when subjects having been pre-exposed to the to-be-conditioned CS exhibited less learning than non-pre-exposed subjects.

First, the development of conditioned freezing was evaluated across the three CS-US pairings by the amount of freezing exhibited over three successive tone-CS presentations (Fig. 4A). LI was evident by increased freezing in the $\mathrm{nPE}$ animals relative to the $\mathrm{PE}$ animals $\left(F_{(1,28)}=6.05 ; p<0.05\right)$. This relative retardation in learning was evident in both the mutant and control mice, especially in trials 2 and 3 when the tone-CS was expected to generate conditioned responding. Although the LI effect appeared somewhat stronger in the mutant relative to the controls, the interaction between pre-exposure and genotype was not significant $\left(F_{(1,28)}=1.76 ; p=0.20\right)$. Given the overall presence of LI across the three trials of CS-US pairing, we conducted a priori contrast to ascertain the statistical presence of LI in the mutant and control groups separately, which revealed a significant presence of LI in the mutant $(p=0.015)$ but not in the controls $(p=0.414)$. The comparison between mutant and control in the nPE condition did not yield any significant group difference $(p=0.16)$.

Twenty-four hours later, the animals were returned to the conditioning context for the assessment of conditioned freezing to the context over a period of $8 \mathrm{~min}$ (Fig. $4 \mathrm{~B}$ ). Although the PE control and $\mathrm{nPE}$ control showed a significant difference in their freezing to the context, no such difference was detected in the mutant. This led to the emergence of a significant interaction between genotype and pre-exposures $\left(F_{(1,28)}=4.86 ; p<0.05\right)$. Post hoc comparison confirmed that a statistically significant difference between PE and $\mathrm{nPE}$ conditions was exclusively found in the control animals $(p=0.012)$. Therefore, it showed that the control mice were not entirely indifferent to the effects of CS pre-exposure before conditioning. The direction of this effect is also in accordance with elemental associative learning theories, suggesting a competition between discrete CS and contextual cues for associative strength with the US. The absence of this effect in the mutant was further accompanied by a tentative increase in contextual freezing in the nPE condition (Fig. 4B): a direct comparison by a restricted ANOVA between nPE mutant and $\mathrm{nPE}$ control revealed that the increase in conditioned freezing to the context seen in the mutant mice approached statistical significance $\left(F_{(1,13)}=4.02 ; p=0.066\right)$.

The generation of the conditioned response to the tone CS was assessed $48 \mathrm{~h}$ after conditioning, when the animals were returned
To directly compare the expression of conditioned freezing to the tone in the nPE condition, an additional ANOVA restricted to the $\mathrm{nPE}$ subjects was conducted. This revealed a near significant main effect of genotype $\left(F_{(1,13)}=4.18 ; p=0.06\right)$, which was accompanied by a significant interaction between genotype and bins $\left(F_{(7,91)}=2.97 ; p=0.02\right)$. Post hoc comparison indicated that mutant/nPE mice exhibited a significantly higher level of freezing than control/nPE from the third to the seventh bins of the tone CS presentation CS ( $p$ values $<0.05$ ).

These results are consistent with the expectation of an enhanced NMDAR function in the mutant mice. The observation that these animals exhibited LI when the pre-exposure/conditioning parameters were insufficient to yield significant LI in the control is suggestive of enhanced selective attention.

CamKII $\alpha$ Cre:Glyt $1 \mathrm{tm} 1.2 \mathrm{fl} / \mathrm{fl}$ mice show enhanced acquisition of active avoidance with an augmentation of the latent inhibition effect

To further test the generality of the results obtained in the conditioned freezing experiment, we next subjected the animals (14 mutant and 17 controls) to another associative learning paradigm (i.e., active avoidance) using a design that again allowed the assessment of the LI effect. Here, LI would be observed if animals that were exposed to the signal for foot shock before acquisition training learned to avoid the foot shock at a slower pace than the non-pre-exposed subjects.

The pre-exposure session was uneventful: a $2 \times 2$ (genotype $\times$ pre-exposure) ANOVA of the total number of spontaneous shuttles recorded on the pre-exposure session yielded no significant effect. The acquisition of the conditioned avoidance response on the following day was indexed by the speed to shuttle (= one/ latency to response from CS onset). Learning was evident in all groups as indicated by a reduction in the mean shuttle speed over successive blocks of 10 trials (Fig. 5). This was confirmed by a $2 \times$ $2 \times 10$ (genotype $\times$ pre-exposure $\times$ blocks) split-plot ANOVA of response latency, which only yielded a main effect of blocks $\left(F_{(9,243)}=27.10 ; p<0.001\right)$.

An overall presence of LI was suggested by the near-significant pre-exposure $\times$ blocks interaction $\left(F_{(9,243)}=1.87 ; p=0.058\right)$. However, LI was more clearly seen in the mutant mice, as mu$\operatorname{tant} / \mathrm{nPE}$ showed a shorter latency to shuttle compared with the mutant/PE (Fig. $5 \mathrm{~A}$ ). In contrast, LI was visibly absent in control mice. We therefore conducted a priori contrast to ascertain the presence of LI in mutant and control mice: a significant presence of LI was detected in the mutant $(p=0.046)$ but not in the 
control ( $p=0.69)$. Similar to the pattern of results obtained in the LI conditioned freezing experiment (Fig. $4 A, C$ ), the enhancement of LI seen in the mutants was also associated with faster learning in the mutant/nPE relative to the control/nPE. Restricted direct comparison between these two groups yielded a significant genotype $\times$ blocks interaction $\left(F_{(9,126)}=\right.$ 1.98; $p<0.05$ ), suggesting that the mutant had acquired the avoidance response at a faster rate than the control in the same condition.

CamKII $\alpha$ Cre:Glyt1tm1.2fl/fl mice show an augmentation of the latent inhibition effect in the conditioned taste aversion paradigm

To test the hypothesis that the mutation led to enhanced LI, we compared the expression of LI in mutant mice $(n=17)$ and littermate controls $(n=13)$ in yet another associative learning paradigm, namely, conditioned taste aversion, in which reduced conditioned aversion to the taste CS in the pre-exposed subjects relative to non-pre-exposed subject constitutes LI.

Baseline, pre-exposure, and conditioning phases of the experiment were uneventful. All animals readily drank from the drinking tubes by the end of the baseline phase, with the mutant and control mice consuming on average $1.31 \pm 0.10$ and $1.51 \pm 0.15 \mathrm{~g}$ of water, respectively, in the first drinking period on the final baseline day. A $2 \times 2$ (genotype $\times$ preexposure) ANOVA of liquid consumed in the pre-exposure session yielded no significant effect (Table 1). In the conditioning session, the $\mathrm{PE}$ animals consumed a higher amount of liquid $\left(F_{(1,26)}=7.12 ; p<0.05\right)$ (Table 1). This effect reflected a reduction in taste neophobia in the PE subjects and was equivalently seen in both mutant and control mice as indicated by post hoc Fisher's LSD comparisons ( $p$ values $<0.05$ ).

In the test session, the consumption of sucrose solution in absolute amount and in terms of percentage of total liquid consumed were submitted to $2 \times 2$ (genotype $\times$ pre-exposure) ANOVA. In each case, the overall main effect of preexposure approached statistical significance (sucrose solution consumed, $F_{(1,26)}$ $=3.89, p=0.06$; percentage of sucrose solution consumption, $F_{(1,26)}=3.39, p=$ $0.08)$, although they might be considered so if a one-tailed criterion was applied with the alternative hypothesis of $\mathrm{H}_{\mathrm{A}}: \mu_{\mathrm{PE}}>\mu_{\mathrm{NPE}}$ (instead of $\mathrm{H}_{\mathrm{A}}$ : $\left.\mu_{\mathrm{PE}} \neq \mu_{\mathrm{NPE}}\right)$ in accordance with the expected direction of the latent inhibition effect.

As illustrated in Figure 6, the latent inhibition effect was again
A B

Conditioning

\section{Context freezing}
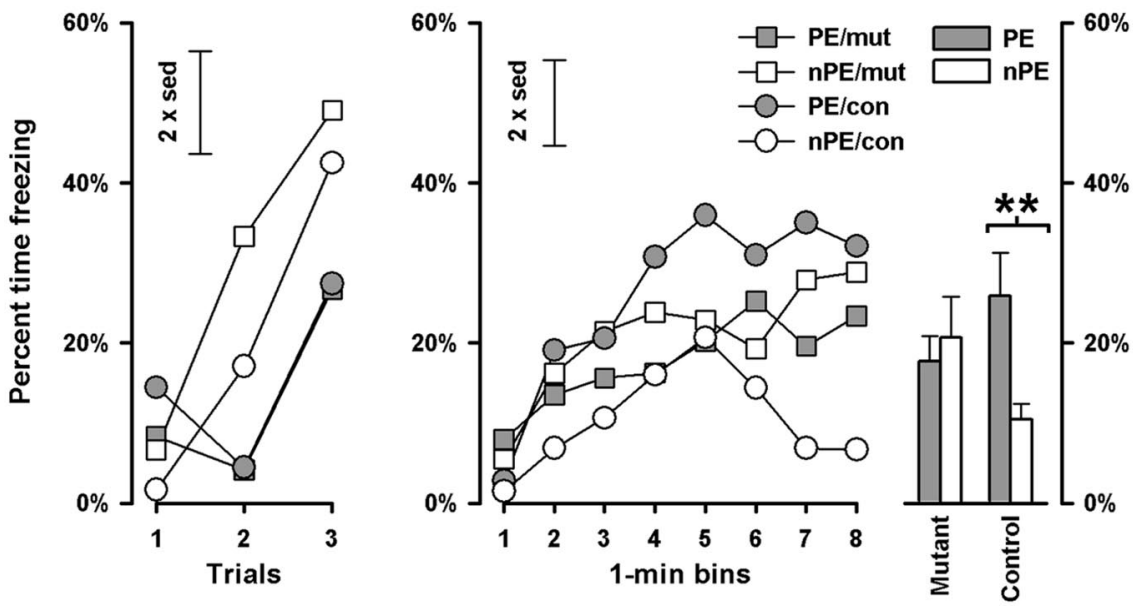

0
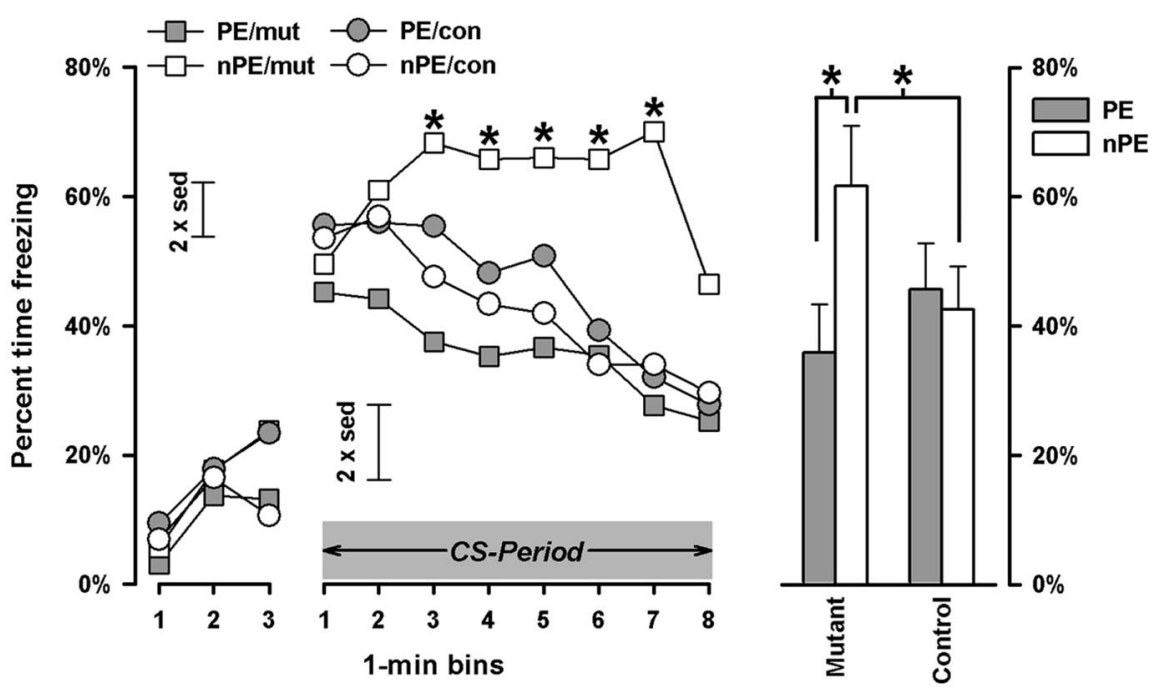

Figure 4. Latent inhibition in the conditioned freezing paradigm. $A$, Expression of freezing behavior toward the tone-CS across the three conditioning trials immediately after pre-exposure. The histogram to the right illustrates the level of freezing averaged across the three trials. Freezing in the PE subjects tended to be lower than in the nPE subjects, constituting the latent inhibition effect. Mutant/PE, $n=8 ;$ mutant $/ \mathrm{nPE}, n=7$; control/PE, $n=9 ;$ control/nPE, $n=8$. B. Freezing to the context $24 \mathrm{~h}$ after conditioning. This is expressed as a function of $1 \mathrm{~min}$ bins on the left and as the overall means on the right. The error bar on the left refers to twice the SE of difference derived from the mean square error term associated with the three-way (genotype $X$ pre-exposures $X$ bins) interaction. Error bars on the right correspond to the SEM associated with the respective mean values. The asterisks denote a significant difference between PE controls and nPE controls, as indicated by Fisher's LSD comparison, following the emergence of the significant interaction between genotype and pre-exposures $(p<0.01)$. C, Freezing to the tone CS $48 \mathrm{~h}$ after conditioning. Error bars in the line plots refer to twice the SE of difference derived from the appropriate mean square error term taken from the ANOVA of the 3 min pre-CS period or the 8 min CS period. The histogram on the right illustrates the mean levels of freezing averaged across the entire $8 \mathrm{~min}$ CS period. The presence of the latent inhibition effect in the mutant mice is evident by significant increase in conditioned freezing in the mutant/nPE than in the mutant/PE group $\left({ }^{*} p<0.05\right.$ based on a priori contrast). The control group did not exhibit a significant latent inhibition effect. This contrast led to the interaction between genotype and pre-exposures attained significance $(p<0.05)$. Comparison between mutant/nPE and control/nPE also indicated a significant difference $(p<0.05)$. Additional analysis restricted to nPE subjects indicates increased conditioned freezing in the mutant compared with the control group between the third and seventh bins in the CS period. All values refer to mean \pm SEM.

more clearly seen in the mutant than in the control mice. Although the interaction between genotype and pre-exposure failed to attain statistical significance $(F<1)$, this impression was in line with the results of the previous two experiments. We there- 


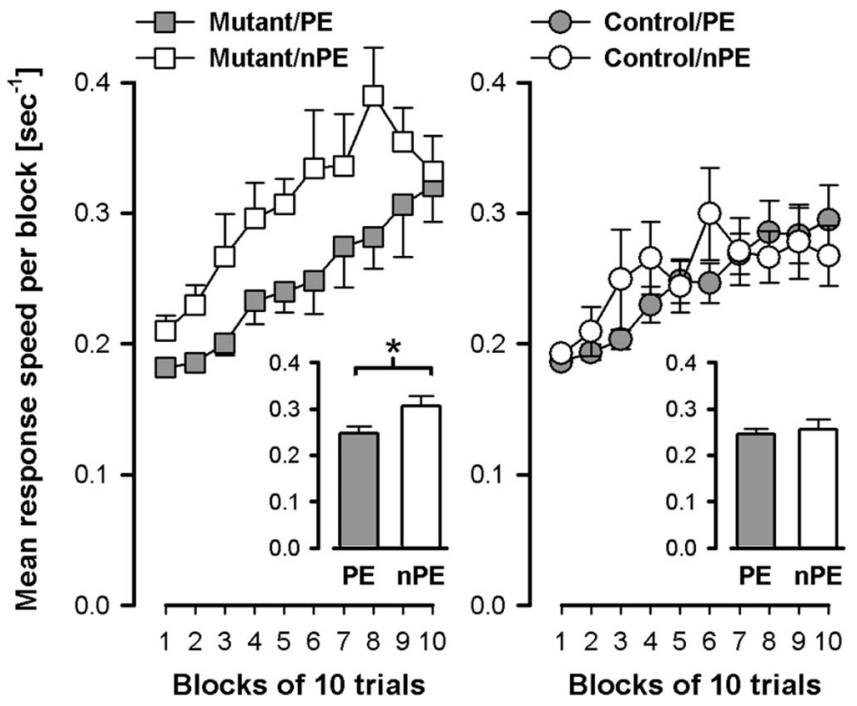

Figure 5. Latent inhibition in conditioned active avoidance learning. Acquisition of the conditioned avoidance response across 10 blocks of 10 trials conducted $24 \mathrm{~h}$ after tone pre-exposure in mutants (left) relative to controls (right). Learning was indexed by response speed (calculated by $1 /$ latency to shuttle from the stimulus noise-onset). A response speed above $(0.2=$ $1 / 5$ ) would constitute an avoidance response. Increasing response speed indicated the acquisition of avoidance learning as training progressed. The mean response speed across the acquisition 100 acquisition trials in each group is illustrated in the histogram. ${ }^{*} p<0.05$, significant difference between PE mutants and $\mathrm{nPE}$ mutants, as indicated by the analysis restricted to the mutant mice. All values refer to mean \pm SEM. Mutant/PE, $n=7 ;$ mutant $/ \mathrm{nPE}, n=7 ;$ control/ $\mathrm{PE}, n=9$; control/nPE, $n=8$.
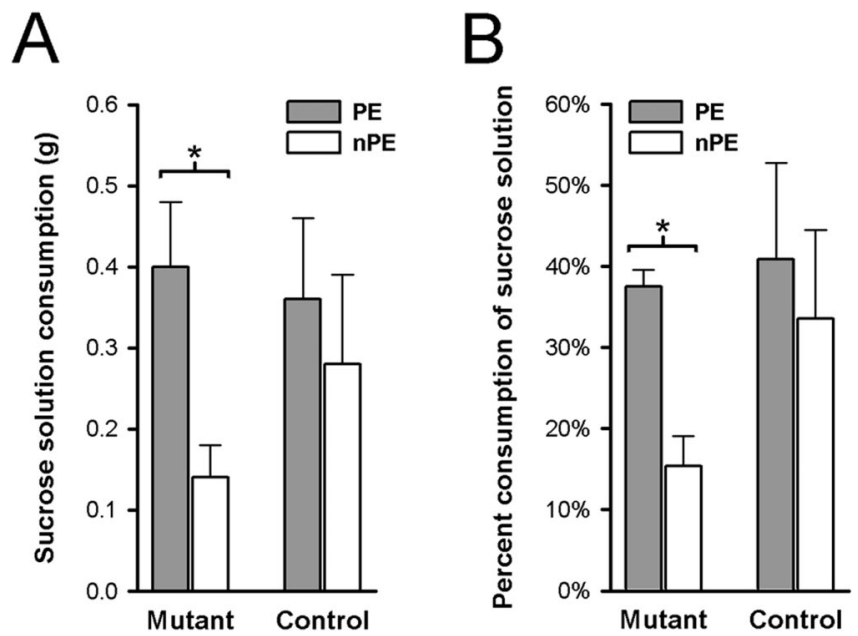

Figure 6. Latent inhibition in conditioned taste aversion. The expression of conditioned taste aversion on the test day ( $24 \mathrm{~h}$ after sucrose-LiCl pairing) was indexed by sucrose solution consumption. This was expressed in absolute amount $(\boldsymbol{A})$ or in the percentage of total liquid consumed in the 30 min test session. The lower the amount of sucrose consumed, the greater the taste aversion. Weaker conditioned aversion in the PE relative to the $\mathrm{nPE}$ condition constitutes the LI effect. LI was significantly seen in the mutant mice in both measures ( ${ }^{*} p<0.05$ ) but not in the control. All values refer to mean $\pm \mathrm{SEM}$. Mutant $/ \mathrm{PE}, n=9 ;$ mutant $/ \mathrm{nPE}, n=8$; control/PE, $n=7$; control $/ \mathrm{nPE}, n=6$.

fore conducted separate restricted ANOVAs to separately evaluate the presence of the latent inhibition effect in the mutant or the control mice. A highly significant effect of pre-exposure, in the direction of latent inhibition, was obtained in the mutant using both measures of sucrose consumption on the test day (absolute amount, $F_{(1,15)}=7.56, p=0.015$; percentage, $F_{(1,15)}=11.57, p=$ 0.004 ) but not in the control animals (both $F$ values $<1$ ). This contrast lent support to the interpretation that the expression of latent inhibition was stronger in the mutant animals. However, direct comparisons between mutant and control restricted to the $\mathrm{nPE}$ condition did not indicate any difference in the magnitude of taste aversion between the two groups $(F$ values $<1)$.

\section{CamKII $\alpha$ Cre:Glyt1tm1.2fl/fl mice exhibit reduced sensitivity} to the motor stimulant effect of psychomimetic drugs

To clarify whether the consistent enhancement of LI seen in the CamKII $\alpha$ Cre:Glyt 1tm1.2fl/fl mice implies a "antipsychotic-like" phenotypic profile, we attempted to assess the animals' reaction to psychostimulant drugs, with the expectation that the mutant mice would exhibit some degree of resistance. To this end, we contrasted the motor stimulant effect of amphetamine (an indirect dopamine receptor agonist) and of phencyclidine (a noncompetitive NMDAR antagonist) to vehicle treatment in nine mutant and 14 littermate control mice. Because of the increased baseline activation of NMDAR function in the mutants, we expected that the stimulatory response to phencyclidine would be reduced. Given that the psychostimulant effects of phencyclidine are also partly attributed to dopamine reuptake inhibition (Johnson and Jones, 1990), we included amphetamine as another psychostimulant drug for comparison, allowing us to test whether an anti-psychostimulant effect would be seen equivalently between the two drugs differing in their principal mode of pharmacological action.

The activity profile over the $2 \mathrm{~h}$ test period is illustrated in Figure 7. Systemic challenge of either amphetamine or phencyclidine at the selected doses led to comparable elevations of locomotor activity in the control animals. The mutation led to a delay of the action of amphetamine and partially reduced the impact of amphetamine over the first $20 \mathrm{~min}$ of the test (Fig. $7 \mathrm{~A}$ ). In contrast, the mutation drastically attenuated the response to phencyclidine that was apparent from 15 min onwards (Fig. 7B). No difference was observed between mutant and control in locomotor activity after vehicle saline injection (Fig. 7C).

The impression that the expression of drug effects over bins differed between the mutant and control mice is confirmed by a $2 \times 3 \times 24$ (genotype $\times$ drug $\times$ bins) ANOVA of (square-root transformed) distance moved per 5 min bins, which yielded a significant three-way interaction $\left(F_{(46,414)}=1.69 ; p<0.005\right)$. This was accompanied by a main effect of drug $\left(F_{(2,18)}=8.89\right.$; $p=0.002)$, bins $\left(F_{(21,414)}=15.90 ; p<0.001\right)$, and their interaction $\left(F_{(46,414)}=2.18 ; p<0.001\right)$.

Additional analyses restricted to each drug condition were conducted to ascertain the presence of a genotype effect in each case. When confined to the amphetamine condition, the interaction between genotype and bins attained statistical significance $\left(F_{(23,128)}=2.24 ; p=0.002\right)$. Post hoc comparisons indicated that the activity level of the mutant-amphetamine group was significantly below that of the control-amphetamine group in the first four bins $(p<0.05)$. The main effect of genotype did not attain significance $(p=0.96)$, indicating that the overall activity level (under amphetamine) did not differ between the two groups. In contrast, the two-way ANOVA restricted to the phencyclidine condition revealed a main effect of genotype $\left(F_{(1,6)}=6.52 ; p<\right.$ $0.05)$. Finally, the analysis restricted to the vehicle condition did not yield any significant effect of genotype or its interaction with bins (both $F$ values $<1$ ).

The preferential efficacy of the mutation against the motor stimulating effect of phencyclidine is consistent with the fact that deletion of neuronal GlyT1 in the forebrain selectively enhances 
Table 1. Summary of the liquid consumption on the days of pre-exposure, conditioning, and test days in the conditioned taste aversion experiment

\begin{tabular}{|c|c|c|c|c|}
\hline & $\begin{array}{l}\text { Mutant PE } \\
(n=0)\end{array}$ & $\begin{array}{l}\text { Mutant NPE } \\
(n=8)\end{array}$ & $\begin{array}{l}\text { Control PE } \\
(n=7)\end{array}$ & $\begin{array}{l}\text { Control NPE } \\
(n=6)\end{array}$ \\
\hline \multicolumn{5}{|l|}{ Latent inhibition in conditioned taste aversion } \\
\hline Pre-exposure: sucrose solution consumption (g) & $1.77 \pm 0.08$ & & $1.57 \pm 0.19$ & \\
\hline water consumption (g) & & $1.46 \pm 0.08$ & & $1.50 \pm 0.12$ \\
\hline Conditioning: sucrose solution consumption (g) & $1.94 \pm 0.08$ & $1.76 \pm 0.10$ & $2.10 \pm 0.14$ & $1.67 \pm 0.14$ \\
\hline Test day: total liquid consumption (g) & $1.09 \pm 0.15$ & $0.93 \pm 0.11$ & $0.91 \pm 0.13$ & $0.97 \pm 0.25$ \\
\hline
\end{tabular}

See Figure 6 for the critical measures of conditioned taste aversion. All values refer to group mean \pm SEM.

NMDAR functions, with limited direct effects on other neurotransmitter systems.

\section{Discussion}

The forebrain and neuron-specific deletion of Gly 1 achieved here has enabled us to provide a functional analysis of a highly specific subset of GlyT1. We demonstrate that disruption of GlyT1-mediated glycine reuptake, restricted to forebrain neurons, represents an effective strategy to selectively enhance NMDAR activity, affect associative learning, and modulate an example of selective learning, namely the latent inhibition effect.

\section{Neuronal specificity of GlyT1 disruption}

Here, we used Cre-mediated recombination of a conditional Glyt1 allele, driven by the forebrain and neuron-specific CamKII $\alpha$ promoter. CamKII $\alpha$ is a serinethreonine protein kinase, with its expression restricted to neurons of forebrain structures (Mayford et al., 1996). It is therefore reasonable to conclude that GlyT1 has selectively been deleted from forebrain neurons in our CamKII $\alpha$ Cre: Glyt $1 \mathrm{tm} 1.2 \mathrm{fl} / \mathrm{fl}$ mice. This has a drastic impact on glycine transport in forebrain as indicated by the comparison of synaptosomal $\left[{ }^{3} \mathrm{H}\right]$ glycine uptake in CamKII $\alpha$ Cre:Glyt $1 \mathrm{tm} 1.2 \mathrm{fl} / \mathrm{fl}$ and Glyt $1 \mathrm{tm} 1.2 \mathrm{fl} / \mathrm{fl}$ mice. The observed reduction of $V_{\max }$ in the mutant mice (Fig. $2 \mathrm{~B}$ ) is striking, considering that Cre-mediated recombination is expected to essentially spare astrocytic GlyT1-mediated glycine uptake. This implies an elevation of glycine concentration in the microenvironment of forebrain (predominantly glutamatergic) synapses in the CamKII $\alpha$ Cre:Glyt $1 \mathrm{tm} 1.2 \mathrm{fl} / \mathrm{fl}$ mice and implies that the function of neuronal GlyT1 has been underestimated previously (Tsai et al., 2004). This hypothesis was confirmed by the 2.15-fold increase in the NMDA/AMPA response ratio recorded in hippocampal pyramidal neurons of CamKII $\alpha$ Cre: Glyt $1 \mathrm{tm} 1.2 \mathrm{fl} / \mathrm{fl}$ mice compared with Glyt $1 \mathrm{tm} 1.2 \mathrm{fl} / \mathrm{fl}$ mice (Fig. 3). Despite the presence of astrocytic GlyT1, the magnitude of the enhancement seen here is in excess of that reported in mice with a heterozygous constitutive disruption of GlyT1, with an increase of $\sim 1.36$ - to 1.71-fold relative to control mice (Tsai et al., 2004; Gabernet et al., 2005). Therefore, the reported elevation of the NMDA/AMPA response ratio in the heterozygous knock-out mice is likely attributable to the partial loss of neuronal GlyT1, implying that the astrocytic GlyT1 may not be a major determinant for the control of NMDAR functions.
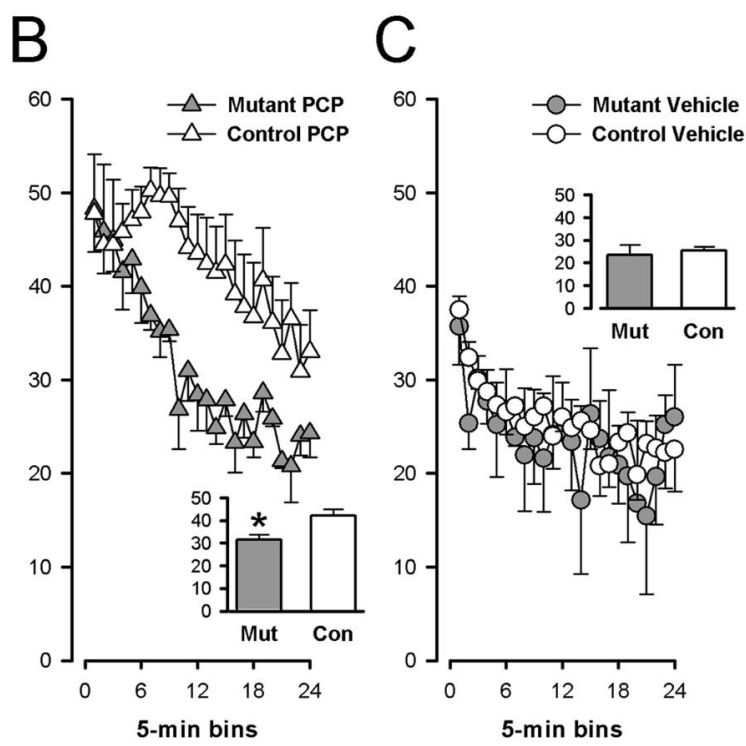

Figure 7. The locomotor effect after systemic amphetamine $(\boldsymbol{A})$, phencyclidine $(\boldsymbol{B})$, or saline vehicle $(\boldsymbol{C})$ treatment. Locomotor activity was measured by distance moved of the animal's center of gravity sampled at a rate of $5 \mathrm{~Hz}$ and summed into successive $5 \mathrm{~min}$ bins over the $2 \mathrm{~h}$ test period. A square-root transformation was performed before statistical analysis to better conform to the homogeneity of variance assumption of parametric ANOVA. The inset embedded within each line graph illustrates the overall 列 the asterisk denotes the significant overall difference between mutant and control ( $\left.{ }^{*} p<0.05\right)$. All values refer to mean \pm SEM. Amph, Amphetamine; PCP, phencyclidine. Mutant/Amph, $n=3$; mutant/PCP, $n=3$; mutant/vehicle, $n=3$; control/Amph, $n=5$; control $/ P C P, n=5$; control/vehicle, $n=4$.

Effects on associative learning and its control by selective attention

The molecular disruption of forebrain neuronal GlyT1 has achieved a level of specificity that is otherwise unattainable by pharmacological means. It has afforded us the opportunity to evaluate the contributions of this subset of GlyT1 to associative learning and, in particular, to the phenomenon known as latent inhibition (Lubow and Moore, 1959). LI is one of the ways in which selectivity in associative learning can be demonstrated, in the sense that not all potential CSs have an equivalent capacity to form an effective $\mathrm{CS} \rightarrow$ US association. A number of animal learning theories explain LI as a form of learned inattention, in which subjects learn to ignore, tune out, or reduce attention to stimuli that appear irrelevant (Mackintosh, 1973; Wagner, 1978; Lubow, 1989). Alternatively, LI has also been characterized as a form of proactive interference in which the CS $\rightarrow$ no consequence relationship experienced by subjects during preexposure phase interferes with the retrieval of an effective CS $\rightarrow$ US association acquired subsequently as the two stimuli are explicitly paired (Bouton, 1991, 1993; Kraemer and Spear, 1991, 1993). As a result, the inconsistent associative histories of the CS can compete for behavioral control in response to the CS, and the readiness for the more recent CS $\rightarrow$ US relationship to command behavior is re- 
ferred to as "behavioral switching" (Weiner, 1990). Accordingly, disruption and augmentation of LI are considered to reflect facilitation and retardation of behavioral switching, respectively.

$\mathrm{LI}$ is disrupted in schizophrenic patients but can be restored after effective neuroleptic treatment (Baruch et al., 1988; Gray et al., 1992). This LI deficiency has been related to the attentional impairment characteristic of schizophrenia (Gray et al., 1991; Moser et al., 2000). It is nonetheless not inconsistent with the alternative view that this represents an indication of enhanced behavioral switching in schizophrenia patients (Weiner, 1990). In animals, LI is abolished by amphetamine and enhanced by both typical and atypical neuroleptics (Weiner and Feldon, 1987; Christison et al., 1988; Feldon and Weiner, 1991; Peters and Joseph, 1993; Dunn et al., 1993), suggesting that LI may constitute an animal model of the attentional deficits associated with schizophrenia (Solomon et al., 1981; Lubow et al., 1987; Weiner, 1990; Feldon and Weiner, 1991; Gray et al., 1991; Moser et al., 2000). The suggestion that elevated levels of glycine can be effective against schizophrenia-related cognitive symptoms (Coyle and Tsai, 2004) has led us to expect a possible LI-enhancing phenotype in the mutant mice with protocols suitable for the demonstration of such an effect.

We evaluated LI in three associative learning paradigms involving aversive unconditional stimuli. It is therefore imperative to first identify possible effects of the mutation on the unconditioned expression of fear. The mutation exerted no effect fearrelated behavior in the elevated plus maze. Spontaneous locomotor activity in the plus maze, the testing boxes in conditioned freezing, the shuttle chambers, and the open field was all unaffected. Hence, any observed changes in conditioned responding are unlikely to be attributed to changes in emotion or changes in spontaneous locomotor activity.

Direct evidence for enhanced associative learning was obtained in conditioned tone-freezing and active avoidance learning. In the $\mathrm{nPE}$ condition, mutant mice expressed a higher level of conditioned freezing across the three tone-shock pairings (Fig. $4 A$ ) and on the subsequent test of context freezing (Fig. $4 B$ ) as well as tone freezing (Fig. $4 C$ ); this effect was statistically the clearest in the final tone freezing test. Similarly, mutant mice in the $\mathrm{nPE}$ condition learned to avoid foot shock by responding to the noise signal at a faster pace than control mice in the same condition (Fig. 5). Given that the motor requirements of the learned responses are incompatible between the two tests, the increased conditioned responding that is evident in both paradigms cannot be accounted for by an effect of the mutation on motor behavior. Furthermore, a similar trend of enhanced associative learning in mutant/nPE relative to control/nPE was also present in the conditioned taste aversion experiment, in which learning was indexed by a preference test (Fig. 6), although the increase in taste aversion developed in the mutant/nPE relative to the control/nPE animals did not achieve statistical significance. Enhanced memory retention was tentatively suggested in constitutive heterozygous GlyT1 knock-out mice (Tsai et al., 2004). We now show that a deficit of forebrain GlyT1 is sufficient for an improvement of the acquisition as well as retention of associative learning.

Regarding the effect of the mutation on the expression of LI, a highly consistent picture has emerged across all three tests: a robust and clear LI was demonstrated in the mutant against a weak level of LI in the control mice (Figs. 4-6). In each case, the parameters chosen did not favor the robust expression of LI in the control. This qualitative difference is likely to reflect a quantitative bias in the mutant toward the expression of LI. Psychologi- cally, this may represent an enhancement of learned inattention (Gray et al., 1991) or a suppression of behavioral switching (Weiner, 1990). In combination with the effect of the mutation on associative learning as such (as confirmed by data restricted to the nPE condition), the observed augmentation of LI always appears to be attributed to a difference between mutant and control in the $\mathrm{nPE}$ rather than the PE condition. The impact of the mutation on LI therefore does not conform to the LI enhancement typically seen after neuroleptic medication, which was primarily mediated via an effect on the PE condition (Moser et al., 2000). The combined effect of enhanced associative learning and potentiation of the stimulus pre-exposure effect, the resultant augmentation of LI, thus appears dissimilar to that reported after systemic GlyT1 blockade by ALX 5407 (Lipina et al., 2005). This dissimilarity is not surprising given that the drug did not enhance associative learning, and it cannot discriminate between neuronal and astrocytic GlyT1.

Nevertheless, the conclusion that selective forebrain neuronal GlyT1 disruption entails antipsychotic properties appears to be justified. The application of LI in animal models of schizophrenia based on selective brain lesions (Yee et al., 1995; Gal et al., 2005; Pothuizen et al., 2005) or molecular manipulation (Miyakawa et al., 2003) demonstrates that the resulting disruption of LI is often accompanied by reduced learning in the $\mathrm{nPE}$ condition. Importantly, the reduced conditioning in the nPE condition seen in these animal models matches the observation made in schizophrenia patients (Baruch et al., 1988), and it may reflect aspects of cognitive impairment. Thus, we propose that the enhancement of NMDAR function and the concomitant disruption of LI demonstrated in the CamKII $\alpha$ Cre:Glyt $1 \mathrm{tm} 1.2 \mathrm{fl} / \mathrm{fl}$ mice is indicative for the potential of neuronal GlyT1 blockade in the forebrain as an effective intervention against the dysfunction in attentional control or behavioral switching mechanism and the cognitive impairment characteristic of schizophrenia.

\section{Reduced sensitivity to psychomimetic drugs}

To clarify further whether the CamKII $\alpha$ Cre:Glyt $1 \mathrm{tm} 1.2 \mathrm{fl} / \mathrm{fl}$ mice possess an antipsychotic-like phenotypic profile, we assessed the motor stimulant effect of systemic amphetamine and phencyclidine. Both drugs are known to exacerbate and induce psychotic symptoms in humans. The mutation delayed the onset of the motor stimulant effect of amphetamine and substantially attenuated the response to phencyclidine (Fig. 7). This effect can be attributed to the increased baseline activation of NMDAR function in the mutants and therefore the functional efficacy of a given concentration of phencyclidine to block the NMDAR should be reduced. In contrast, enhanced NMDAR activity in the mutant mice was only effective in delaying the initial impact of amphetamine, and any resistance incurred by the intrinsic elevation of NMDAR activity was eventually overcome by the sustained elevation of dopamine release. This suggests that interaction between glutamate and dopamine transmission was somewhat affected by the specific deletion of GlyT1 from forebrain neurons.

In contrast, in heterozygous constitutive GlyT1 knock-out mice with a deficit of both glial and neuronal GlyT1 in the entire brain (Tsai et al., 2004), the motor stimulating effect of amphetamine or MK-801 (dizocilpine, another noncompetitive NMDAR antagonist) was not affected. At the same time, although this mutation exhibited resistance to the disruptive effect of amphetamine on prepulse inhibition of the acoustic startle reflex, it exacerbated the disruptive effective of MK-801 in the 
same test. These illustrate that intricate differences do exist between the functional relevance of neuronal and astrocytic GlyT1.

\section{Conclusion}

Mice with neuronal GlyT1 deletion restricted to the forebrain enhance associative learning and its control by experiencedependent selective learning, thus mirroring the psychological deficits characteristic of schizophrenia. Our results further highlight the importance of distinguishing between neuronal and astrocytic GlyT1 in the development of novel compounds designed to interfere with its regulatory function on NMDAR activity.

\section{References}

Aragon C, Lopez-Corcuera B (2005) Glycine transporters: crucial roles of pharmacological interest revealed by gene deletion. Trends Pharmacol Sci 26:283-286.

Baruch I, Hemsley D, Gray JA (1988) Differential performance of acute and chronic schizophrenic in a latent inhibition task. J Nerv Ment Dis 176:598-606.

Bergeron R, Meyer TM, Coyle JT, Greene RW (1998) Modulation of $\mathrm{N}$-methyl-D-aspartate receptor function by glycine transport. Proc Natl Acad Sci USA 95:15730-15734.

Bouton ME (1991) Context and retrieval in extinction and in other examples of interference in simple associative learning. In: Current topics in animal learning: brain, emotion, and cognition (Dachowski LW, Flaherty CF, eds), pp 25-52. Hillsdale, NJ: Lawrence Erlbaum.

Bouton ME (1993) Context, time, and memory retrieval in the interference paradigms in Pavlovian learning. Psychological Bull 114:80-99.

Christison GW, Atwater GE, Dunn LA, Kilts CD (1988) Haloperidol enhancement of LI: relation to therapeutic action. Biol Psychiatry 23:746-749.

Coyle JT, Tsai G (2004) NMDA receptor function, neuroplasticity, and the pathophysiology of schizophrenia. Int Rev Neurobiol 59:491-515.

Cubelos B, Gimenez C, Zafra F (2005a) Localization of the GLYT1 glycine transporter at glutamatergic synapses in the rat brain. Cereb Cortex 15:448-459.

Cubelos B, Gonzales-Gonzales IM, Gimenez C, Zafra F (2005b) The scaffolding protein PSD-95 interacts with the glycine transporter GLYT1 and impairs its internalization. J Neurochem 95:1047-1058.

Danysz W, Parsons AC (1998) Glycine and N-methyl-D-aspartate receptors: physiological significance and possible therapeutic applications. Pharmacol Rev 50:597-664.

Davis S, Butcher SP, Morris RG (1992) The NMDA receptor antagonist D-2-amino-5-phosphonopentanoate (D-AP5) impairs spatial learning and LTP in vivo at intracerebral concentrations comparable to those that block LTP in vitro. J Neurosci 12:21-34.

Dunn LA, Atwater GE, Kilts CD (1993) Effects of antipsychotic drugs on latent inhibition: sensitivity and specificity of animal behavioral model of clinical drug action. Psychopharmacology (Berl) 112:315-323.

Eulenburg V, Armsen W, Betz H, Gomeza J (2005) Glycine transporters: essential regulators of neurotransmission. Trends Biochem Sci $30: 325-333$.

Farber NB (2003) The NMDA receptor hypofunction model of psychosis. Ann NY Acad Sci 1003:119-130.

Feldon J, Weiner I (1991) The latent inhibition model of schizophrenic attentional disorder: haloperidol and sulpiride enhance rats' ability to ignore irrelevant stimuli. Biol Psychiatry 29:635-646.

Gabernet L, Pauly-Evers M, Schwerdel C, Lentz M, Bluethmann H, Vogt K, Alberati D, Mohler H, Boison D (2005) Enhancement of the NMDA receptor function by reduction of glycine transporter-1 expression. Neurosci Lett 373:79-84

Gal G, Schiller D, Weiner I (2005) Latent inhibition is disrupted by nucleus accumbens shell lesion but is abnormally persistent following entire nucleus accumbens lesion: the neural site controlling the expression and disruption of the stimulus preexposure effect. Behav Brain Res 162:246-255.

Gomeza J, Hulsmann S, Ohno K, Eulenburg V, Szoke K, Richter D, Betz H (2003) Inactivation of the glycine transporter 1 gene discloses vital role of glial glycine uptake in glycinergic inhibition. Neuron 40:785-796.

Gray JA, Feldon J, Rawlins JNP, Hemsley DR, Smith AD (1991) The neuropsychology of schizophrenia. Behav Brain Res 14:1-84.
Gray NS, Hemsley DR, Gray JA (1992) Abolition of latent inhibition in acute, but not chronic schizophrenics. Neurol Psychiatry Brain Res $1: 83-89$.

Hauser J, Rudolph U, Keist R, Mohler H, Feldon J, Yee BK (2005) Hippocampal alpha5 subunit-containing $\mathrm{GABA}_{\mathrm{A}}$ receptors modulate the expression of prepulse inhibition. Mol Psychiatry 10:201-207.

Johnson KM, Jones SM (1990) Neuropharmacology of phencyclidine: basic mechanisms and therapeutic potential. Annu Rev Pharmacol Toxicol 30:707-750.

Kinney GG, Sur C, Burno M, Mallorga PJ, Williams JB, Figueroa DJ, Wittmann M, Lemaire W, Conn PJ (2003) The glycine transporter type 1 inhibitor $N$-[3-(4'-fluorophenyl)-3-(4'-phenylphenoxy)propyl]sarcosine potentiates NMDA receptor-mediated responses in vivo and produces an antipsychotic profile in rodent behavior. J Neurosci 23:7586-7591.

Kraemer PJ, Spear NE (1991) The effect of nonreinforced stimulus exposure on the strength of a conditioned taste aversion as a function of retention interval: do intent inhibition and extinction involve a shared process. Animal Learning Behav 20:1-7.

Kraemer PJ, Spear NE (1993) Retrieval processes and conditioning. In: Animal cognition. A tribute to Donald A. Riley (Zentall TR, ed), pp 87-110. Hillsdale, NJ: Lawrence Erlbaum.

Le Pen G, Kew J, Alberati D, Borroni E, Heitz MP, Moreau JL (2003) Prepulse inhibition deficits of the startle reflex in neonatal ventral hippocampal-lesioned rats: reversal by glycine and a glycine transporter inhibitor. Biol Psychiatry 54:1162-1170.

Lipina T, Labrie V, Weiner I, Roder J (2005) Modulators of the glycine site on NMDA receptors, D-serine and ALX 5407, display similar beneficial effects to clozapine in mouse models of schizophrenia. Psychopharmacology (Berl) 179:54-67.

Lubow RE (1989) Latent inhibition and conditioned attentional theory. Cambridge: Cambridge UP.

Lubow RE, Moore AU (1959) Latent inhibition: the effect of non-reinforced preexposure to the conditional stimulus. J Comp Physiol Psychol 66:688-694.

Lubow RE, Weiner I, Schlossber A, Baruch I (1987) Latent inhibition and schizophrenia. Bull Psychonomic Soc 25:464-467.

Mackintosh NJ (1973) Stimulus selection: learning to ignore stimuli that predict no change in reinforcement. In: Constraints on learning (Hinde RA, Stevenson-Hinde J, eds), pp 75-96. London: Academic.

Martina M, B-Turcotte ME, Halman S, Tsai G, Tiberi M, Coyle JT, Bergeron $\mathrm{R}$ (2005) Reduced glycine transporter type 1 expression leads to major changes in glutamatergic neurotransmission of CA1 hippocampal neurones in mice. J Physiol (Lond) 563:777-793.

Mayford M, Bach ME, Huang YY, Wang L, Hawkins RD, Kandel ER (1996) Control of memory formation through regulated expression of a CaMKII transgene. Science 274:1678-1683.

Meyer U, Chang de LT, Feldon J, Yee BK (2004) Expression of the CS- and US-pre-exposure effects in the conditioned taste aversion paradigm and their abolition following systemic amphetamine treatment in C57BL6/J mice. Neuropsychopharmacology 29:2140-2148.

Meyer U, Feldon J, Schedlowski M, Yee BK (2005) An immuno-precipitated neurodevelopmental model of schizophrenia. Neurosci Biobehav Rev 29:913-947.

Miyakawa T, Leiter LM, Gerber DJ, Gainetdinov RR, Sotnikova TD, Zeng H, Caron MG, Tonegawa S (2003) Conditional calcineurin knockout mice exhibit multiple abnormal behaviors related to schizophrenia. Proc Natl Acad Sci USA 100:8987-8992.

Morris RG (1989) Synaptic plasticity and learning: selective impairment of learning rats and blockade of long-term potentiation in vivo by the $\mathrm{N}$-methyl-D-aspartate receptor antagonist AP5. J Neurosci 9:3040-3057.

Morris RG, Anderson E, Lynch GS, Baudry M (1986) Selective impairment of learning and blockade of long-term potentiation by an N-methyl-Daspartate receptor antagonist, AP5. Nature 319:774-776.

Moser PC, Hitchcock JM, Lister S, Moran PM (2000) The pharmacology of latent inhibition as an animal model of schizophrenia. Brain Res Rev 33:275-307.

Peters SL, Joseph MH (1993) Haloperidol potentiation of latent inhibition in rats: evidence for a critical role at conditioning rather than preexposure. Behav Pharmacology 4:183-186.

Pothuizen HHJ, Jongen-Relo AL, Feldon J, Yee BK (2005) Latent inhibition of conditioned taste aversion is not disrupted, but can be enhanced, by 
selective nucleus accumbens shell lesions in rats. Neuroscience 137:1119-1130.

Richmond MA, Murphy CA, Pouzet B, Schmid P, Rawlins JNP, Feldon J (1998) A computer controlled analysis of freezing behavior. J Neurosci Methods 86:91-99.

Schweizer C, Balsiger S, Bluethmann H, Mansuy IM, Fritschy J-M, Mohler H, Luscher B (2003) The $\gamma 2$ subunit of $\mathrm{GABA}_{\mathrm{A}}$ receptors is required for maintenance of receptors at mature synapses. Mol Cell Neurosci 24:442-450.

Solomon P, Crider A, Winkelman JW, Turi A, Kamer R, Kaplan LJ (1981) Disrupted latent inhibition in the rat with chronic amphetamine or haloperidol-induced supersensitivity: relationship to schizophrenic attention disorder. Biol Psychiatry 16:519-537.

Tonkiss J, Morris RG, Rawlins JN (1988) Intra-ventricular infusion of the NMDA antagonist AP5 impairs performance on a non-spatial operant DRL task in the rat. Exp Brain Res 73:181-188.

Tsai G, Ralph-Williams RJ, Martina M, Bergeron R, Berger-Sweeney J, Dunham KS, Jiang Z, Caine SB, Coyle JT (2004) Gene knockout of glycine transporter 1: characterization of the behavioral phenotype. Proc Natl Acad Sci USA 101:8485-8490.

Tsien JZ, Chen DF, Gerber D, Tom C, Mercer EH, Anderson DJ, Mayford M,
Kandel ER, Tonegawa S (1996) Subregion- and cell type-restricted gene knockout in mouse brain. Cell 87:1317-1326.

Wagner AR (1978) Expectancies and the priming of STM. In: Cognitive processes in animal behavior (Tighe TJ, Fowler H, Honig WK, eds), pp 177-209. Hillsdale, NJ: Lawrence Erlbaum.

Weiner I (1990) Neural substrate of latent inhibition: the switching model. Psychological Bull 108:442-461.

Weiner I, Feldon J (1987) Facilitation of latent inhibition by haloperidol. Psychopharmacology (Berl) 91:248-253.

Yee BK, Feldon J, Rawlins JNP (1995) Latent inhibition in rats is abolished by NMDA-induced neuronal loss in the retrohippocampal region, but this lesion effect can be prevented by systemic haloperidol treatment. Behav Neurosci 109:227-240.

Yee BK, Hauser J, Dolgov VV, Keist R, Mohler H, Rudolph U, Feldon J (2004) GABA receptors containing the alpha5 subunit mediate the trace effect in aversive and appetitive conditioning and extinction of conditioned fear. Eur J Neurosci 20:1928-1936.

Zafra F, Aragon C, Olivares L, Danbolt NC, Gimenez C, Storm-Mathisen J (1995) Glycine transporters are differentially expressed among CNS cells. J Neurosci 15:3952-3969. 